NRTSC

Technology

On Time

On Target

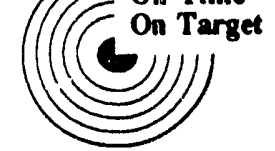

NUCLEAR REACTOR TECHNOLOGY AND SCIENTIFIC COMPUTATIONS

\author{
WS R C - T R - $92-044$
}

KEY WORDS:

Verification

Validation

Benchmarking Diffusion Theory

Time Dependent

RETENTION PERIOD: Lifetime

\title{
VERIFICATION, VALIDATION, AND BENCHMARKING REPORT FOR TRIMHX: \\ A Three Dimensional Hexagonal Transient Diffusion Theory Code (U)
}

B y

T. T. LE

ISSUED: MARCH 1992

SAVANNAH RIVER LABORATORY, AIKEN, SC 29808 


\section{PROIIECT: CERTIFICATION OF REACTOR PHYSICS CODES}

DOCUMENT: WSRC-TR-92.044

TLULE: VERIFICATION, VALIDATION, AND

BENCHMARKING REPOR'T FOR TRIMHX: A Three

Dimensional Hexagonal Transient Diffusion Theory Code (U)

TASK: $\quad 90.44 .1$

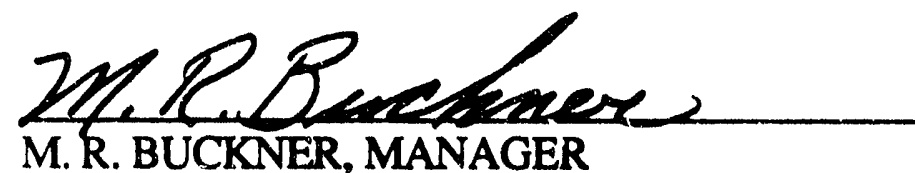

DATE: $\quad 5-25-42$

M. R. BUCKNER, MANAGER

SCIENTIFIC COMPUTATIONS SECTION

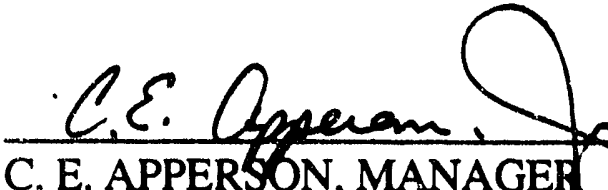

C. E. APPERSON, MANAGER

DATE: $r-21-92$

APPLIED PHYSICS GROUP

Pomald E Puey

R. E. PEVEY, TECHNICAL REVIEWER
DATE:

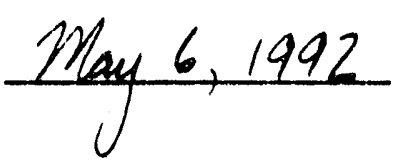


Table of Contents

Page i

\section{TABLE OF CONTENTS}

Page

Table of Contents i

Summary 1

I Introduction to TRIMHX 2

I I Verification 2

III Validation 2

IV. Numerical Test Problems 3

IV.1 Test Problem I 3

IV.2 Test Problem II 5

IV.3 Test Problem III 7

V Pulsed Neutron Experiments 9

VI. Space-Time PDP Experiments 12

VI.1 Two-Dimensional Experiments 12

VI.2 Three-Dimensional Experiments 19

VII Adiabatic Model Test Problem 33

VIII Comparisons with Other Codes 36

VIII.1 Comparison with DIF3D 36

VIII.2 Comparison with DIF3D and FX2-TH 38

IX Comparisons of Initial TRIMHX to GRIMHX Results 43 
WSR C.T R.92.044

March, 1992

Table of Centents Page i

$\mathrm{X}$ Conclusions 45

References 46 


\section{SUMMARY}

This report concerns the verification aud validation of TRIMHX, a transient two and three dimensional hex-z diffusion theory code. The validation was performed to determine the accuracy of the code, and the verification was performed to determine if the code was correctly using the correct theory and that all the subroutines function as required. For TRIMHX, the validation requirement was satisfied by comparing the results of the code with experiments and benchmarking the code against other standard or validated code results. The verification requirement for TRIMHX was performed indirectly since it is impossible and not necessary to reverify a large code like TRIMHX line by line. The extensive operations history of TRIMHX in conjunction with the comparisons against many numerical experiments (exact solutions) and other diffusion theory codes is sufficient to establish that the code is functioning as intended and therefore it is verified.

This report summaries four sets of experiments performed in 1974, 1977, and 1988, two DIF3D/TRIMHX comparison problems performed in 1991, a DIF3D/FX2-TH/TRIMHX comparison problem produced for this report, and the comparison of TRIMHX/GRIMHX initial static calculations. The results of these experiments show that TRIMHX was correctly implemented and is ready to submit into SCMS production mode. 


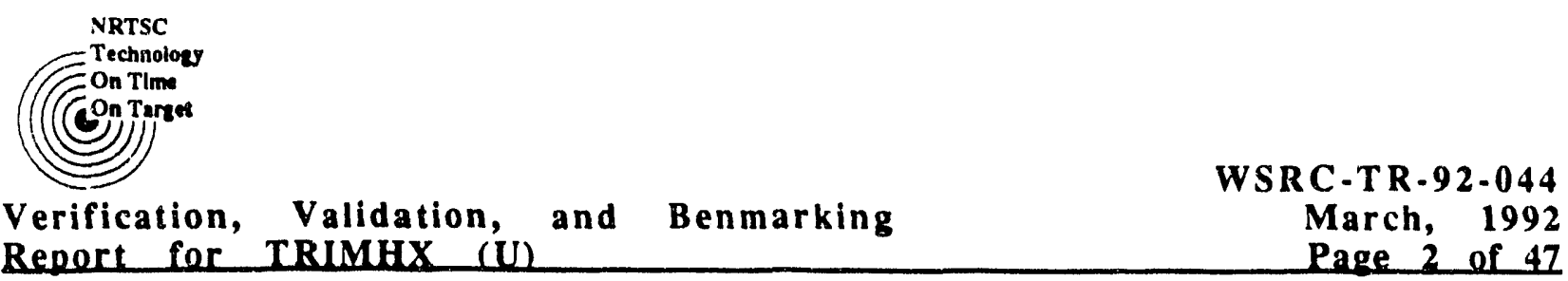

\section{INTRODUCTION TO TRIMHX}

TRIMHX is a fundamental Reactor Analysis tool in use at the Savannah River Site (SRS) and is an integral part of the Generalized Reactor Analysis Subsystem (GRASS). TRIMHX solves the time dependent multigroup neutron diffusion equation in two and three dimensional hexagonal geometry by standard and coarse mesh finite difference methods. The TRIMHX implementation assumes the solution to this equation can be discretized in space, energy, and time. These are industry accepted approaches which can be found in many nuclear engineering books 1,2 . TRIMHX was written by M. R. Buckner and J. W. Stewart at Savannah River Laboratory. The calculational flow and the theory implemented in TRIMHX are discussed in References 3 and 4.

\section{VERIFICATION}

As part of the certification process, TRIMHX has to be verified, a process to ensure that the coding correctly implements the intended calculational methods ${ }^{5}$. Since TRIMHX is a large computer code which was developed long before the current verification requirement was in place, the verification performed at that time was not documented sufficiently to meet current requirements today. Reverify TRIMHX line by line would be a monumental task and it has not been deemed necessary. The extensive operations history of TRIMHX in conjunction with the comparisons against many numerical experiments (exact solutions) and other diffusion theory codes is sufficient to establish that the code is functioning as iniended and therefore satisfies the verification requirement.

\section{VALIDATION}

Validation refers to the process in which the accuracy of the whole code is determined. This process can be performed by comparing the code results with the experimental data, controlled experiments, operational data, or more accurate calculational methods (benchmarks) ${ }^{5}$. For TRIMHX, the validation was performed by comparing the code results with exact solutions, experimental results, results of other validated codes, and the results from industry standard codes. 


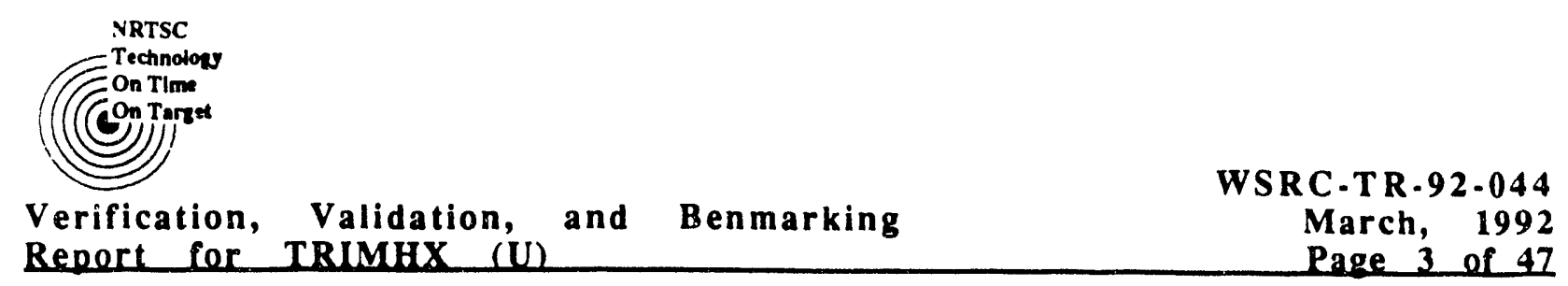

Five sets of test problems and experiments produced in the past, a new test problem, and the comparisons of TRIMHX/GRIMHX initial calculations are described in this report. These sets of test problems and experiments are three numerical test problems performed in 1974, a pulsed neutron experiment performed in 1974, five space-time PDP experiments performed in 1974 and 1977, an adiabatic model test problem performed in 1988, and a comparison with a Nodal Diffusion code DIF3D performed in 1991. The new test problem is a two-dimensional problem from the DIF3D paper published in 1991.

Following are short descriptions and the results of these sets of test problems and experiments. For more details, readers are referred to the given references.

\section{Numerical Test Problems}

These three test problems were performed by M. R. Buckner and J. W. Stewart in 1974 to demonstrate the accuracy of the TRIMHX method6. These test problems have several common characteristics:

1. two energy groups

2. one or six delayed neutron families

3. six-fold sector symmetry in the horizontal plane

4. one mesh point per hex

5. ten axial mesh points for three-dimensional calculations

6. step change in reactivity at time zero.

The results of these test problems are reproduced below. Detailed descriptions and the input data of these test problems can be found in Reference 6.

\section{IV.1 Test Problem I}

This is a bare homogeneous reactor problem with a spatially uniform perturbation in the production cross section. Reference solutions are solutions from the few-group point kinetics equation. The results of a 80 cents perturbation case are given in Table 4.1, and the comparisons of the central flux versus time for five reactivity perturbation cases are sketched 
in Figure 4.1.

Table 4.1: Results for 80 cents Perturbation Case

\begin{tabular}{|c|c|c|c|c|c|}
\hline \multirow{2}{*}{$\begin{array}{l}\text { Time } \\
\text { (sec) }\end{array}$} & \multicolumn{3}{|c|}{ Polat Kinetias } & \multicolumn{2}{|c|}{ 3-D TRIMHX } \\
\hline & $\Delta t=0.5 \mathrm{msec}$ & $\Delta t=5 \mathrm{msec}$ & $\Delta t=50 \mathrm{msec}$ & Transferm & Ne-Trans \\
\hline $\begin{array}{l}0 \\
1 \\
2 \\
3 \\
4 \\
5 \\
6 \\
7\end{array}$ & $\begin{array}{r}1.000 \\
5.896 \\
8.426 \\
11.975 \\
17.018 \\
24.186 \\
34.373 \\
48.850\end{array}$ & $\begin{array}{r}1.000 \\
5.896 \\
8.430 \\
11.985 \\
17.037 \\
24.220 \\
34.430 \\
48.945\end{array}$ & $\begin{array}{r}1.000 \\
5.896 \\
8.477 \\
12.086 \\
17.230 \\
24.563 \\
34.017 \\
49.920\end{array}$ & $\begin{array}{r}1.000 \\
5.874 \\
8.454 \\
12.054 \\
17.184 \\
24.495 \\
34.918 \\
49.798\end{array}$ & $\begin{array}{r}1.000 \\
5.897 \\
8.488 \\
12.100 \\
17.259 \\
24.610 \\
35.095 \\
50.058\end{array}$ \\
\hline
\end{tabular}

Figure 4.1: Normalized Reactor Midpoint Thermal-neutron Flux versus Time for Four Values of Reactivity

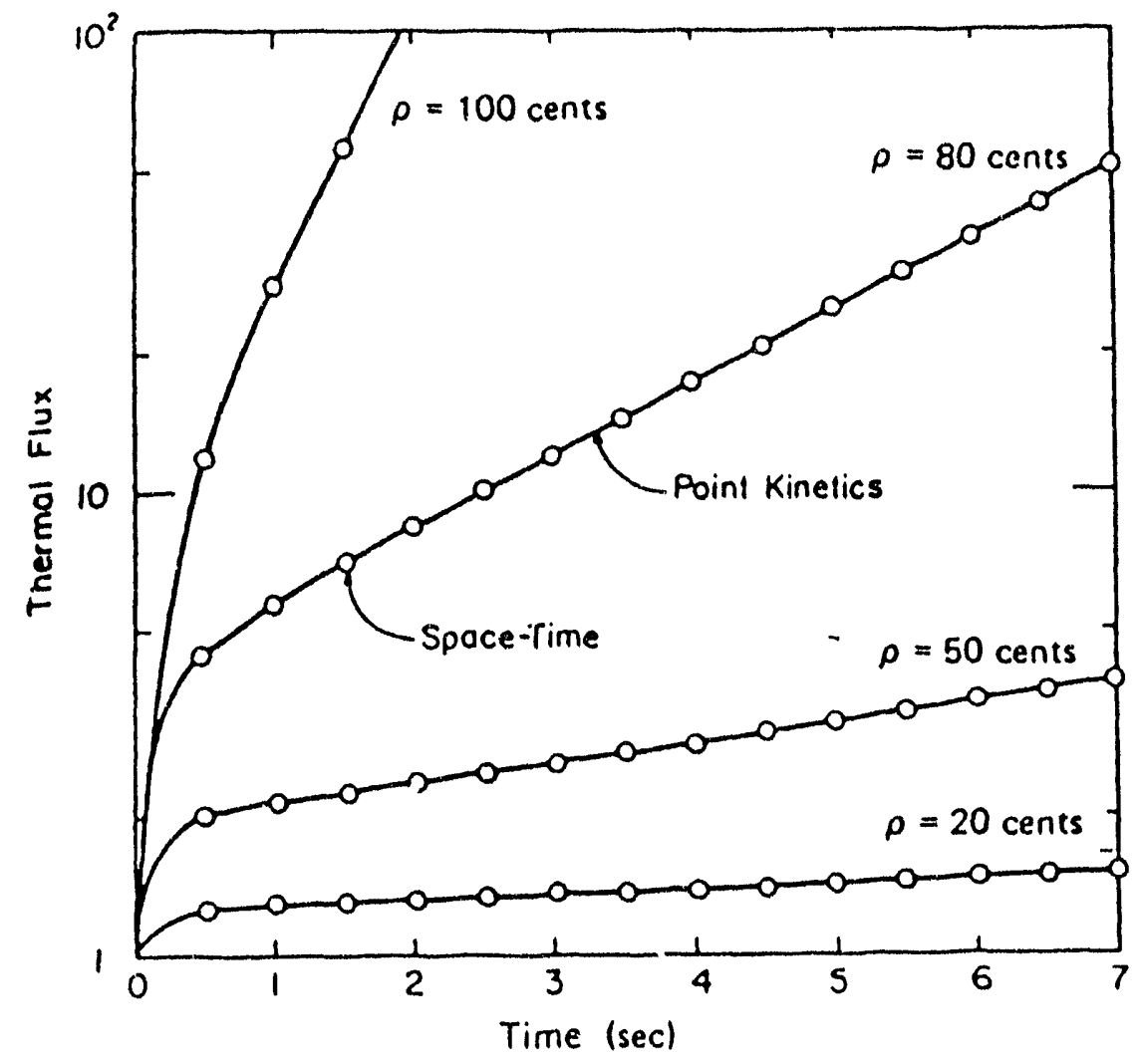




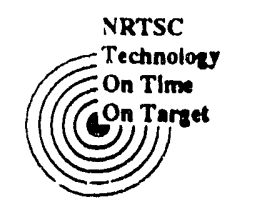

Verification, Validation, and Benmarking

WS R C - T R-92.044

Report for TRIMHX (U)

March, 1992

Page 5 of 47

The results show the excellent agreement between the exact solutions and the TRIMHX solutions. The discrepancies between two solutions are less than $0.5 \%$ for all cases. It is worthwhile to note that TRIMHX with exponential transformations method gives better results than the standard (without exponential transformation) TRIMHX method.

\section{IV.2 Test Problem II}

This is a bare heterogeneous reactor problem with a spatially uniform perturbation in the production cross section. The reactor is made up of thirteen difference materials as shown in Figure 4.2. Reference solutions are also solutions from the few-group point kinetics equation. The results of 80 cents perturbation case are given in Table 4.2. The results show the excellent agreement between the exact solutions and the TRIMHX solutions.

\section{Table 4.2: Results for 80 cents Perturbation Case}

\begin{tabular}{|c|c|c|c|}
\hline \multirow{2}{*}{$\begin{array}{l}\text { Time } \\
(\mathrm{sec})\end{array}$} & \multirow{2}{*}{$\begin{array}{c}\text { Point Kinetics } \\
\Delta t=50 \text { msec }\end{array}$} & \multicolumn{2}{|c|}{ 3-D TRIMHX } \\
\hline & & Transform & Ne-Trans. \\
\hline $\begin{array}{l}0 \\
1 \\
2 \\
3 \\
4 \\
5 \\
6\end{array}$ & $\begin{array}{r}1.000 \\
5.870 \\
8.446 \\
12.039 \\
17.157 \\
24.452 \\
34.848\end{array}$ & $\begin{array}{r}1.000 \\
5.896 \\
8.482 \\
12.096 \\
17.249 \\
24.599 \\
35.084\end{array}$ & $\begin{array}{r}1.000 \\
5.920 \\
8.512 \\
12.142 \\
17.321 \\
24.708 \\
35.248\end{array}$ \\
\hline
\end{tabular}


Figure 4.2: Reactor Geometry for Test Problem II and III (60-deg sector at midplane and axial cross section of the reactor).

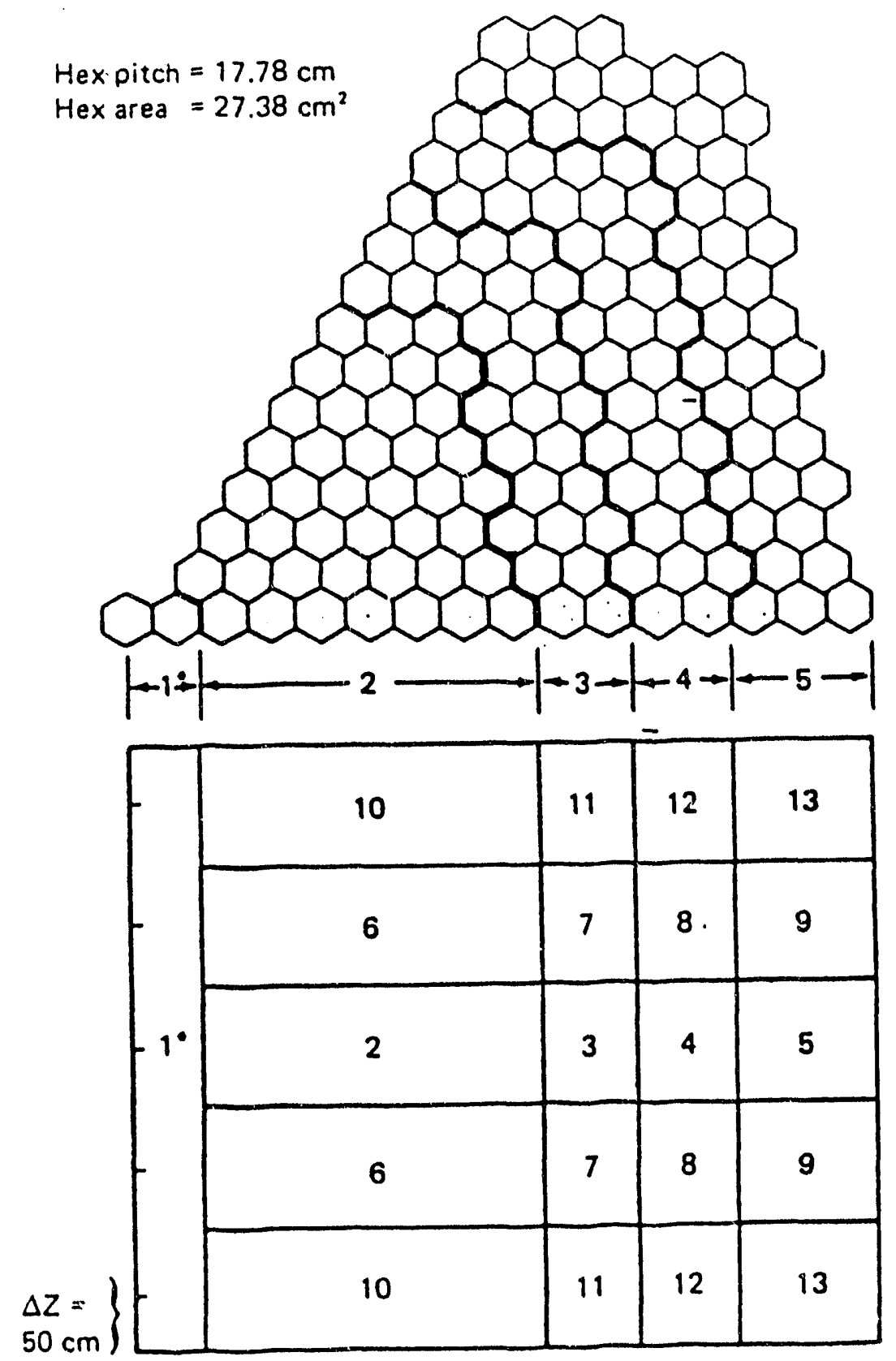




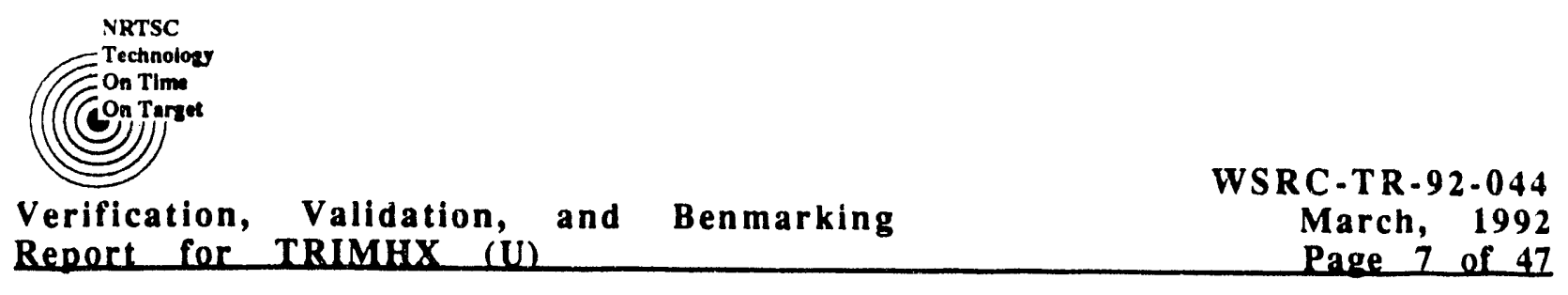

\section{IV.3 Test Problem III}

This is a bare heterogeneous reactor problem as Test Problem II with the local perturbation of thermal absorption cross section in the central patch (center hex plus the six surrounding hexes) up to $-18 \%$. The perturbation was an axially uniform step change at time zero. Since the point kinetics solution is not valid for this problem, a dynamic reactivity was inferred from the asymptotic period found by using a calculated neutron lifetime. The radial distributions of thermal flux at zero and 7 seconds are shown in Figure 4.3 and the TRIMHX results are shown in Table 4.3. These results are for the case of $15 \%$ reduction in thermal absorption cross section. Again, the results show the excellent agreement between the exact solutions and the TRIMHX solutions.

\section{Table 4.3: TRIMHX Results}

\begin{tabular}{|c|c|c|c|c|c|c|}
\hline \multirow{2}{*}{$\begin{array}{l}\text { Time } \\
\text { (sec) }\end{array}$} & \multicolumn{3}{|c|}{ TRIMHX with Transform } & \multicolumn{3}{|c|}{ TRIMHX without Transform } \\
\hline & $\Delta t=5 \mathrm{msec}$ & $\Delta t=25 \mathrm{msec}$ & $\Delta t=50 \mathrm{msec}$ & $\Delta t=5 \mathrm{msec}$ & $\Delta t=25 \mathrm{msec}$ & $\Delta t=50 \mathrm{msec}$ \\
\hline $\begin{array}{l}0.0 \\
0.5 \\
1.0 \\
1.5 \\
2.0 \\
2.5 \\
3.0 \\
3.5 \\
4.0 \\
4.5 \\
5.0\end{array}$ & $\begin{array}{r}1.000 \\
10.647 \\
15.552 \\
20.624 \\
26.988 \\
35.242 \\
46.003 \\
60.044 \\
78.365 \\
102.271 \\
133.458\end{array}$ & $\begin{array}{r}1.000 \\
10.500 \\
15.495 \\
20.623 \\
27.035 \\
35.354 \\
46.210 \\
60.391 \\
78.918 \\
103.121 \\
134.735\end{array}$ & $\begin{array}{r}1.000 \\
10.896 \\
15.477 \\
20.086 \\
27.230 \\
35.563 \\
46.017 \\
61.920 \\
79.860 \\
104.508 \\
136.752\end{array}$ & $\begin{array}{r}1.000 \\
10.874 \\
15.454 \\
20.054 \\
26.184 \\
35.495 \\
45.918 \\
59.798 \\
78.148 \\
101.955 \\
133.003\end{array}$ & $\begin{array}{r}1.000 \\
10.897 \\
15.488 \\
20.100 \\
27.259 \\
35.610 \\
46.095 \\
60.058 \\
79.299 \\
103.646 \\
135.461\end{array}$ & $\begin{array}{r}1.000 \\
10.538 \\
15.581 \\
20.791 \\
27.315 \\
35.793 \\
46.878 \\
61.388 \\
80.384 \\
105.255 \\
137.812\end{array}$ \\
\hline
\end{tabular}


Figure 4.3: Thermal Neutron Flux at Reactor-Midplane versus Reactor Radius (linear plot).

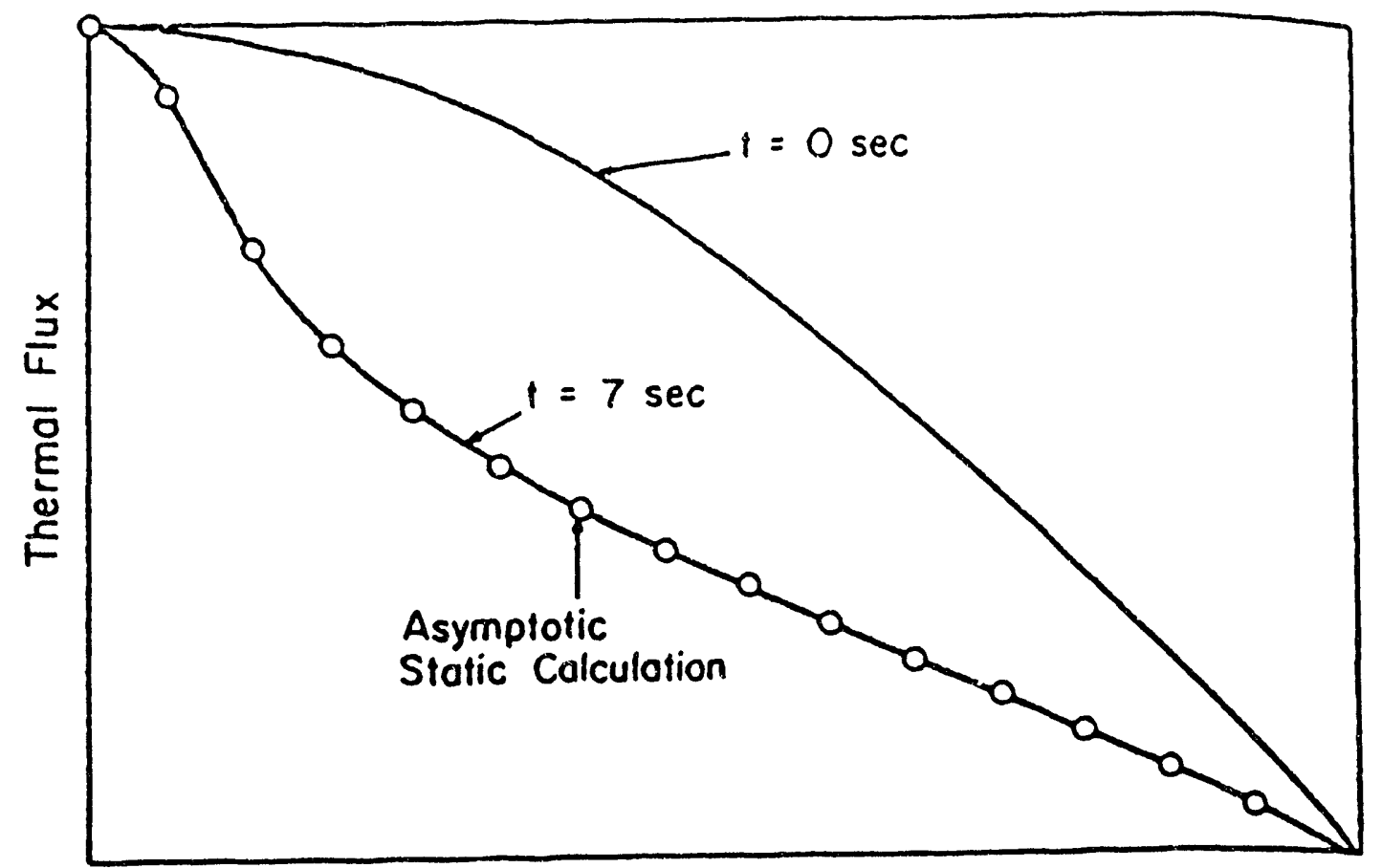

Radius 


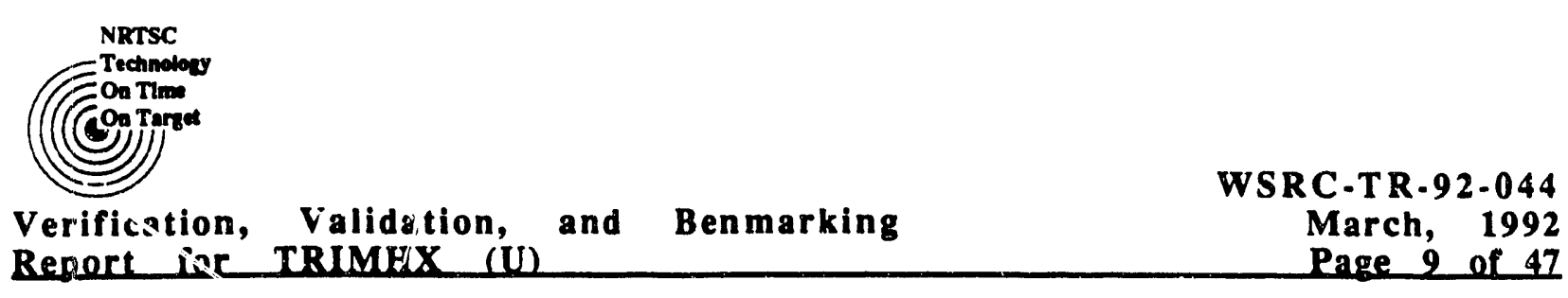

\section{Pulsed Neutron Experiments}

These experiments were carried out by P. B. Parks and J. W. Stewart in $1974^{7}$. The experiments were performed in the Process Development Pile (PDP) at Savannah River Laboratory (SRL). The tests involved a hexagonal core surrounded by a hexagonal reflector in which control assemblies and fuel assemblies (E-D charge) were representative of typical SRS lattices. The core was tilen pulsed by a ${ }^{3} \mathrm{H}(\mathrm{d}, \mathrm{n})^{4} \mathrm{He}$ accelerator source and TRIMHX calculations with 2 energy groups, 60 degree symmetry, 3 points per hex, 20 axial mesh points, and 6 groups of delayed neutron family were performed for comparison.

To eliminate ihe uncertainties of the input diffusion parameters as well as the errors contributed to the problem from the initial static calculation, two assumptions were incorporated into the TRIMHX analysis. The first of these is the normalization of diffusion parameters by assuming that the discrepancies between calculated and measured values of a case are due to errors in the input diffusion parameters. The diffusion parameters were adjusted so that the measured and calculated prompt neutron respond are identical in the static calculation of the reactivity. These diffusion parameters were used for the TRIMHX calculations. The second assumption was the derivation of static subcritical reactivity from the normalized diffusion parameters. This was done by a code of the same neutronic model as TRIMHX code, i.e., the static few-group neutron diffusion theory GRIMHX ${ }^{3}$ code.

One critical and three subcritical measurements were made on this lattice. The critical measurement established the critical water height at 241.50 $\mathrm{cm}$. The subcritical pulsed experiments were then performed with the water height of $210.73 \mathrm{~cm}, 174.71 \mathrm{~cm}$, and $153.13 \mathrm{~cm}$. The vertical and radial schematics of the experimental arrangement are shown in Figure 5.1 . 
NRTSC

Technolowy

Con Time

Contin

Verification,

Validation, and Benmarking

WSR C-TR-92-044

Report for TRIMHX (U)

Mari:h, 1992

Page 10 of 47

Figure 5.1: Vertical and Radial Display of the Experiment
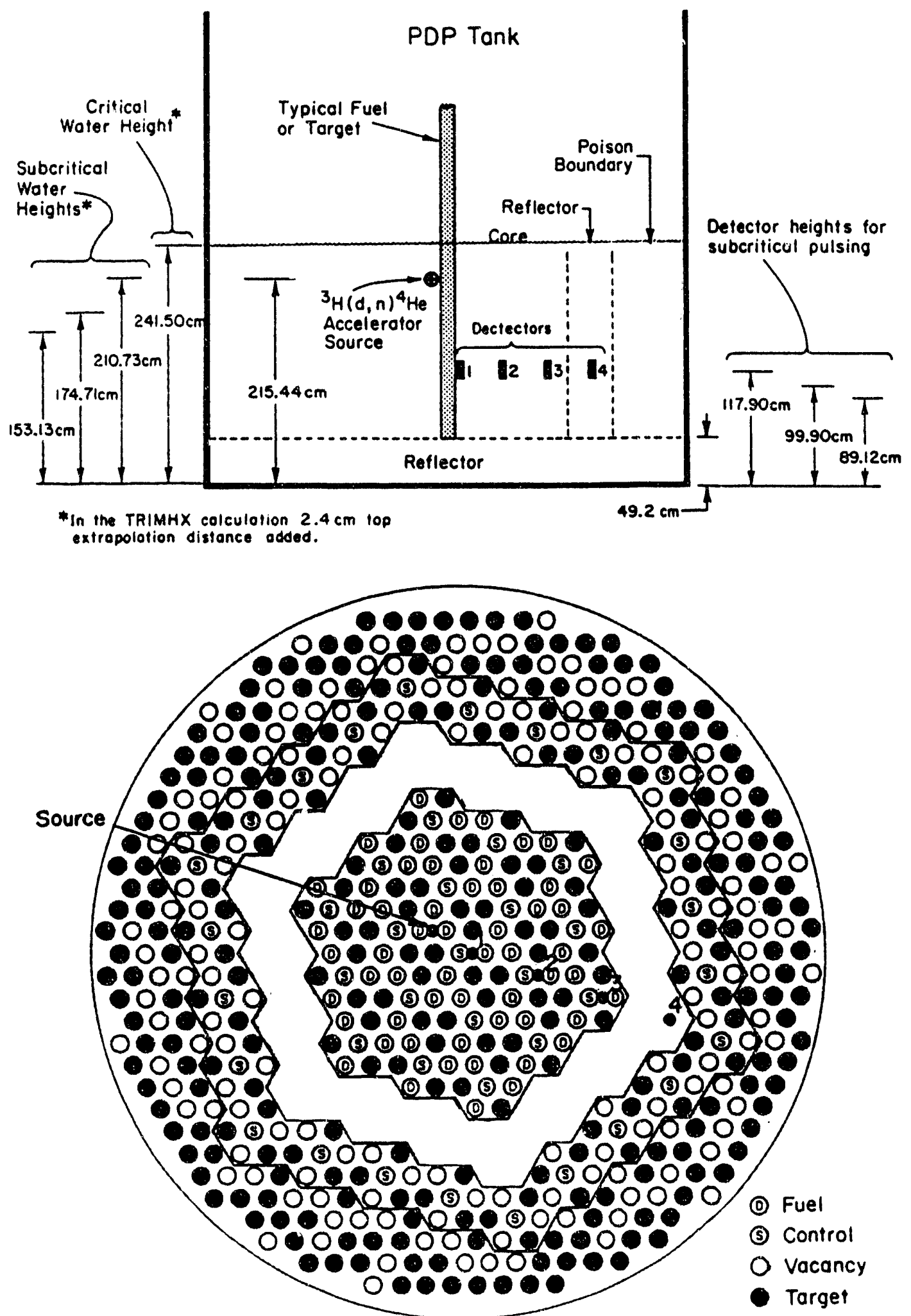


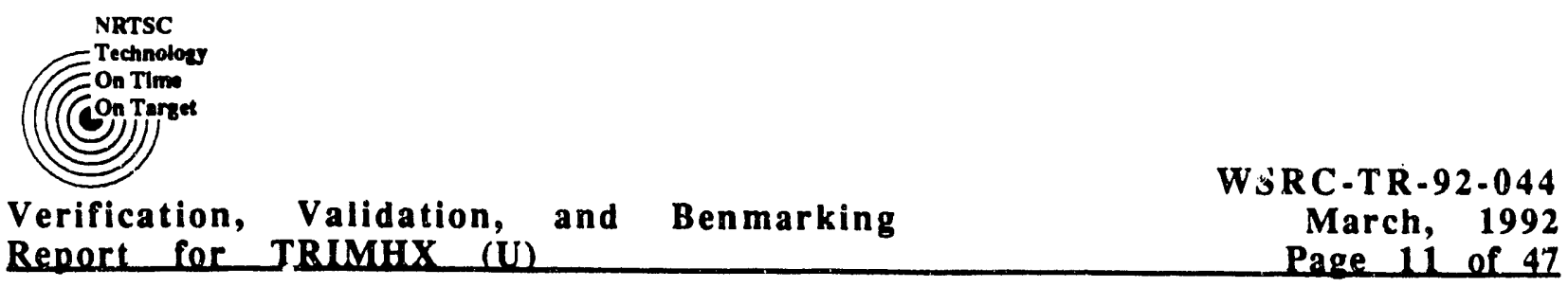

In these reflected lattice experiments, kinetic distortion as well as delayed neutron and prompt harmonics were present. These harmonics problems invalidated the conventional analyses of Gozani's, Sjostrand, and GarelisRussell7. The space-time calculational method, however, is unaffected by these harmonics problems. To the extent the two-group treatment was adequate, the effects of delayed and prompt harmonics and kinetic distortions were directly included in the space-time calculation of the experiments. It is instructive to compare the conventional results with the space-time method results. Table 5.1 below lists the space-time reactivities and the conventional reactivities found using data only after the fundamental mode had been established.

Table 5.1: Measured and Calculated Reactivities for the Reflected Lattice in the PDP

\begin{tabular}{|c|c|c|c|c|c|}
\hline $\begin{array}{l}\text { Water } \\
\text { Height }\end{array}$ & $\begin{array}{l}\text { Normalized } \\
\text { TRIMHX }\end{array}$ & Detector & Gozani & Garelis-Russeld & sjostrand \\
\hline 241.50 & -0.00101 & & & & \\
\hline 210.73 & -0.01128 & $\begin{array}{l}1 \\
2 \\
3 \\
4\end{array}$ & $\begin{array}{l}-0.00918 \\
-0.00952 \\
-0.01043 \\
-0.01157\end{array}$ & $\begin{array}{l}-0.00855 \\
-0.00939 \\
-0.01049 \\
-0.01068\end{array}$ & $\begin{array}{l}-0.01038 \\
-0.00995 \\
-0.00939 \\
-0.00914\end{array}$ \\
\hline 174.71 & -0.03139 & $\begin{array}{l}1 \\
2 \\
3 \\
4\end{array}$ & $\begin{array}{l}-0.02278 \\
-0.02430 \\
-0.03122 \\
-0.03818\end{array}$ & $\begin{array}{l}-0.02269 \\
-0.02344 \\
-0.02967 \\
-0.03515\end{array}$ & $\begin{array}{l}-0.02805 \\
-0.02669 \\
-0.02971 \\
-0.02972\end{array}$ \\
\hline 153.13 & -0.05234 & $\begin{array}{l}1 \\
2 \\
3 \\
4\end{array}$ & $\begin{array}{l}-0.03737 \\
-0.03854 \\
-0.04673 \\
-0.07129\end{array}$ & $\begin{array}{l}-0.03937 \\
-0.04193 \\
-0.04675 \\
-0.06628\end{array}$ & $\begin{array}{l}-0.04857 \\
-0.04553 \\
-0.04412 \\
-0.05427\end{array}$ \\
\hline
\end{tabular}

Comparisons of the calculated to measured data showed that overall prompt neutron response to a pulsed source was well represented. These comparisons were made against experiments at critical conditions and at varying degrees of subcriticality. In all cases there was good agreement between the measured and calculated $k_{\text {eff. }}$. Readers are referred to References 7 and 8 for more details about this experiment. 


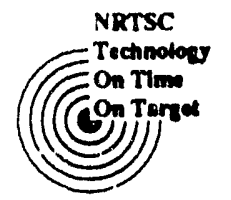

Verification, Validation, and Benmarking

WS RC-TR-92-044

Report for TRIMHX (U)

March, 1992

Page 12 of 47

\section{Space-time PDP Experiments}

These five experiments were performed by P. B. Parks, N. P. Baumann, C. E. Jewell, W. G. Winn, R. L. Currie in 1974 and 1977 for testing the TRIMHX code9-10. The experiments were performed in the $\mathrm{D}_{2} \mathrm{O}$ moderates Process Development Pile (PDP) at the Savannah River Laboratory, and the measured data were used to compare against the TRIMHX calculated results. To reduce the uncertainties of the input diffusion parameters as well as the insufficiencies of the static lattice contribution to errors in the initial static calculation, a normalization procedure has been applied to the production cross secticiss to force the calculated static eigenvalue, static flux distribution, and perturbation wurth to agree with the measured values. There were two 2-dimensional experiments and three 3limensional experiments performed during this study. The comparison results and short descriptions of each experiment are described below. Detailed descriptions and the input data of these experiments are given in References 9 and 10 .

\section{VI1 TWO-DIMENSIONAL EXPERIMENTS}

\section{2-D Experiment \#1}

In this first two-dimensional experiment, the control assemblies were loaded so that the radial flux shape was peaked at the center. The reactivity transients were initiated by dropping two or more $235 \mathrm{U}$-bearing rods into the lattice at the desired perturbation sites. To maximize flux tilts, Gang 3 location was chosen as perturbation sites, and the definition of flux tilt is:

$$
\begin{aligned}
& \text { Tilt }=\frac{[\phi(t) / \phi(0)]_{A}}{[\phi(t) / \phi(0)]_{B}} \\
& \text { where } \phi(t) \text { is time dependent flux, } \\
& \phi(0) \text { is initial flux, and } \\
& \text { A, B are positions. }
\end{aligned}
$$

Base lattice flux distribution was measured by gold pin activation method, 
and flux tilts were measured by four detectors which are placed in the lattice interstitial positions. Figures 6.1 and 6.2 show the experiment geometry and the TRIMHX calculation geometry. Figure 6.3 shows the measured and calculated flux tilts. Due to computing cost, TRIMHX was used to determine the calculated flux tilt up to $90 \%$ of the asymptotic value and GRIMHX was used to determine flux tilt at the asymptotic value.

Figure 6.1: Preparation of perturbation, dummy sites, and location of detectors and gold pins in Exp\#1.

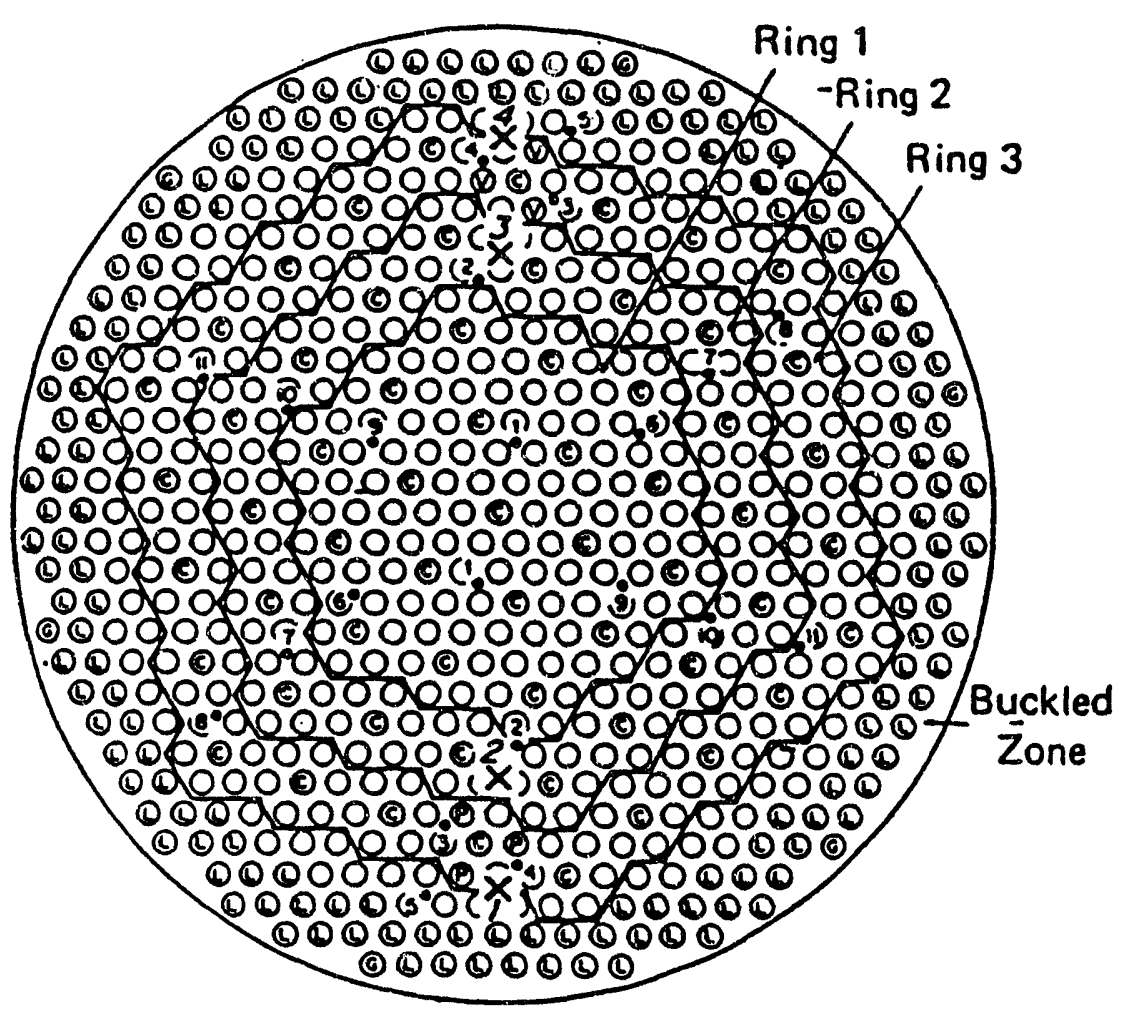

\begin{tabular}{|ll|}
\hline O & Fuel \\
C) & Control \\
(C) & Lithium \\
() & Vacancy \\
(D) & Thimble - no rod \\
(D) & Thimble - with ${ }^{235} U$ rod \\
$\times$ & 10 B ion chamber location \\
- & Gold pin location \\
\hline
\end{tabular}




\section{Figure 6.2: Geometry of TRIMHX calculations of Exp\#1.}

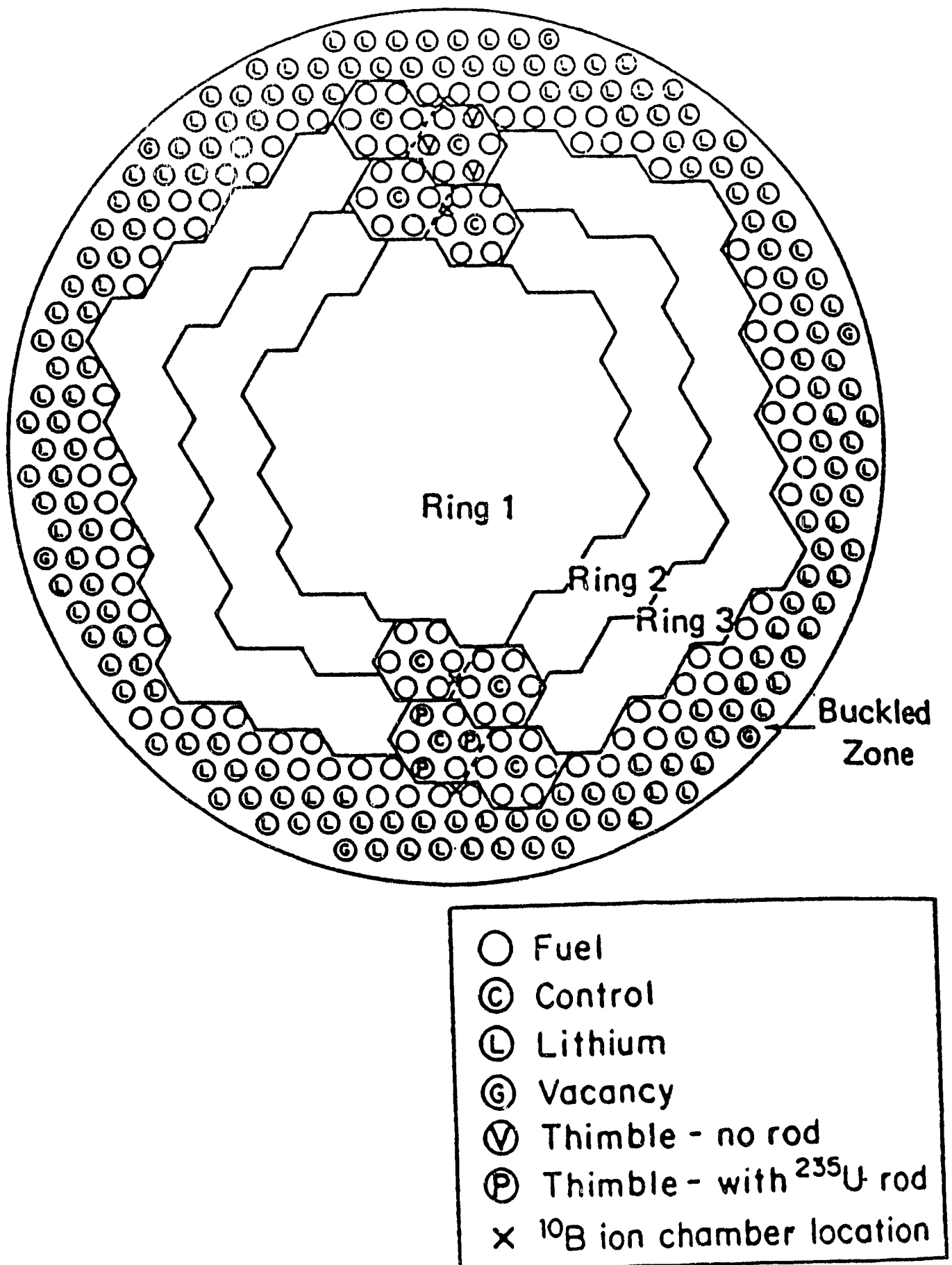


Figure 6.3: Measured and calculated flux tilts from Exp\#1.

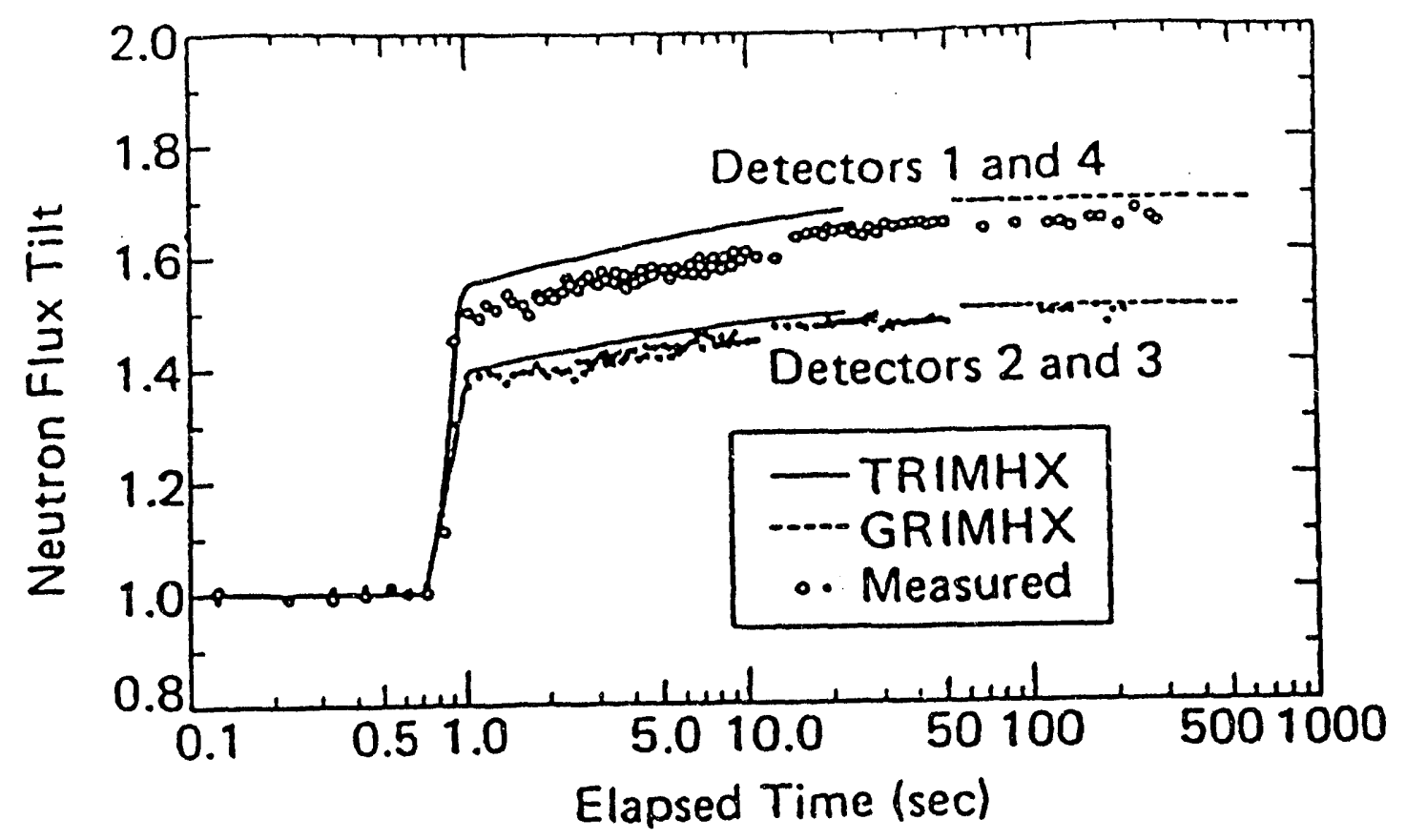

\section{2-D Experiment \#2}

In this second two-dimensional experiment, the control assemblies were loaded so that the radial flux shape was depressed at the center. The reactivity transients were initiated by dropping two perturbation rods into the desirec fuel sites. Base flux distribution was also measured by gold pin activation method but the flux tilts were measured by eight detectors placed in the actual fuel sites. Figures 6.4 and 6.5 show the experiment geometry and the TRIMHX calculation geometry. Figure 6.6 shows the measured and calculated flux tilts. Again, due to computing cost, TRIMHX was used to determine the calculated flux tilt up to $90 \%$ of the asymptotic value and GRIMHX was used to determine flux tilt at the asymptotic value. 
Figure 6.4: Preparation of perturbation, dummy sites, and location of detectors and gold pins in Exp\#2.

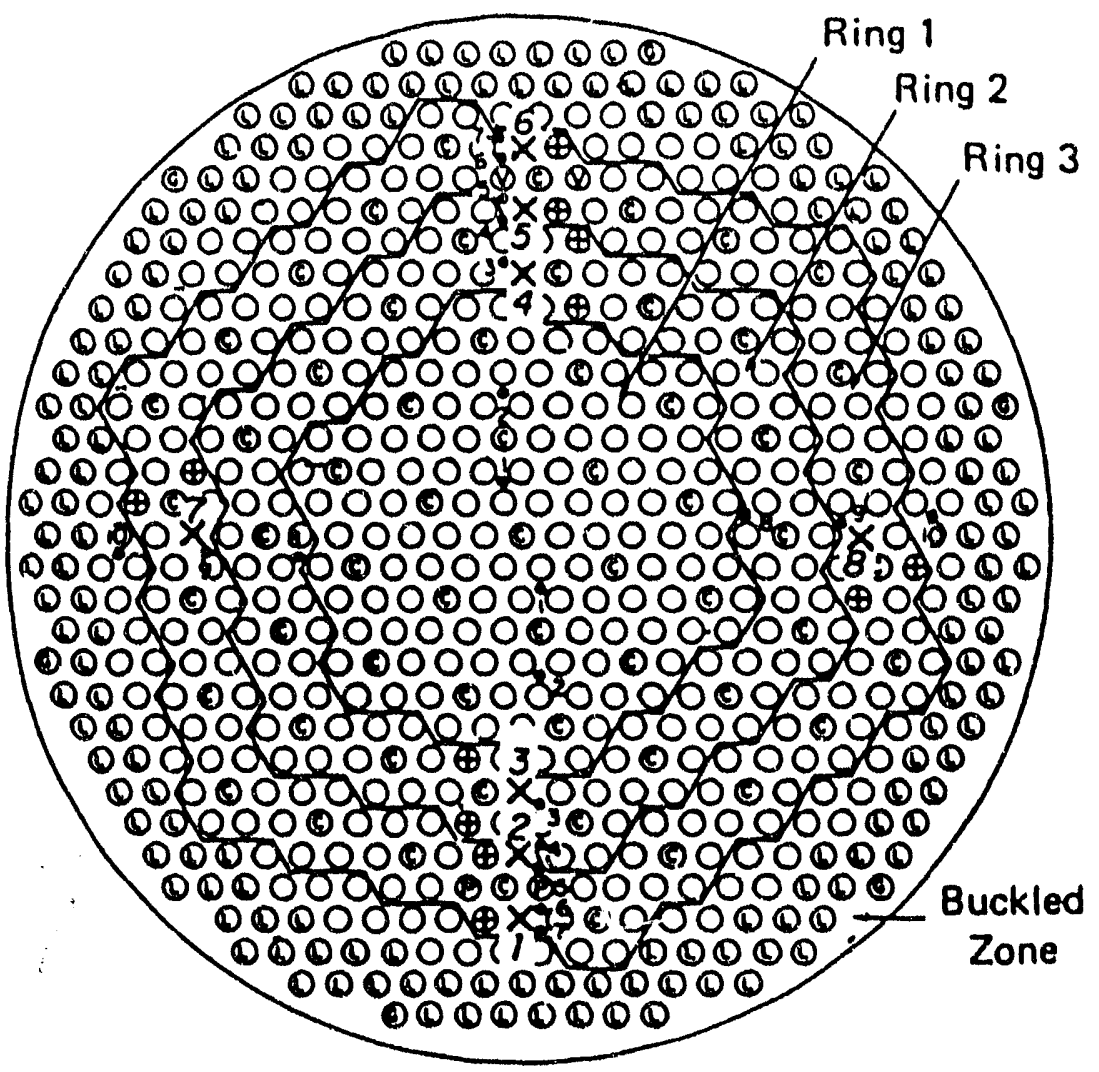

Fuel

(C) Control

(L) Lithium

(a) Vacancy

(1) Thimble - no rod

(B) Thimble - with ${ }^{235} \mathrm{U}$ rod

$\otimes{ }^{10} B$ ion chamber inside dry well in fuel element

$\bigoplus$ Fuel element with dry well but no detector

- Gold pin location 


\section{Figure 6.5: Geometry of TRIMHX calculations of Exp\#2.}

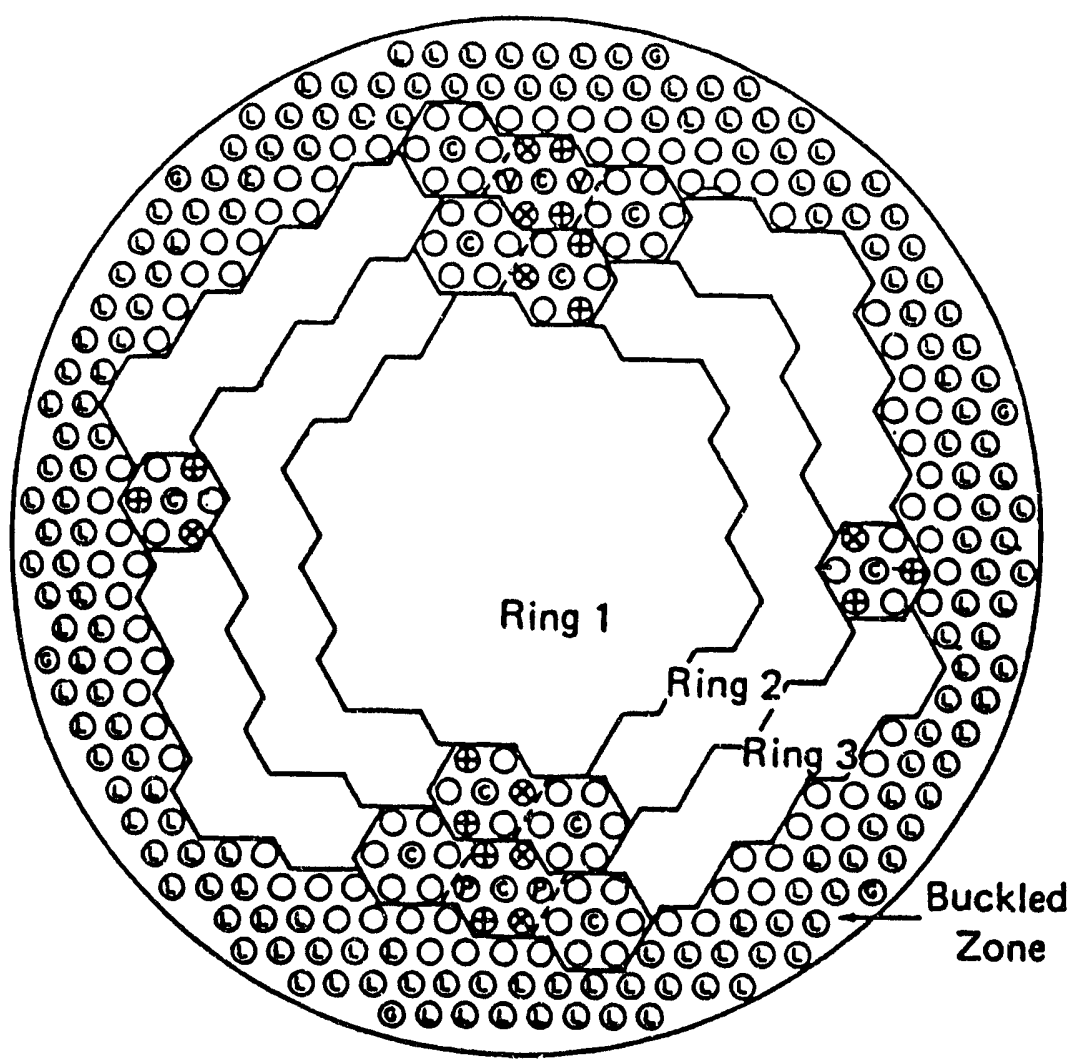

O Fuel

(C) Control

(L) Lithium

(a) Vacancy

(1) Thimble - no rod

(B) Thimble - with ${ }^{235} \mathrm{U}$ rod

(8) ${ }^{10} \mathrm{~B}$ ion chamber inside dry well in fuel element

$\bigoplus$ Fuel element with dry well but no detector 
Figure 6.6: Measured and calculated flux tilts from Exp\#2.
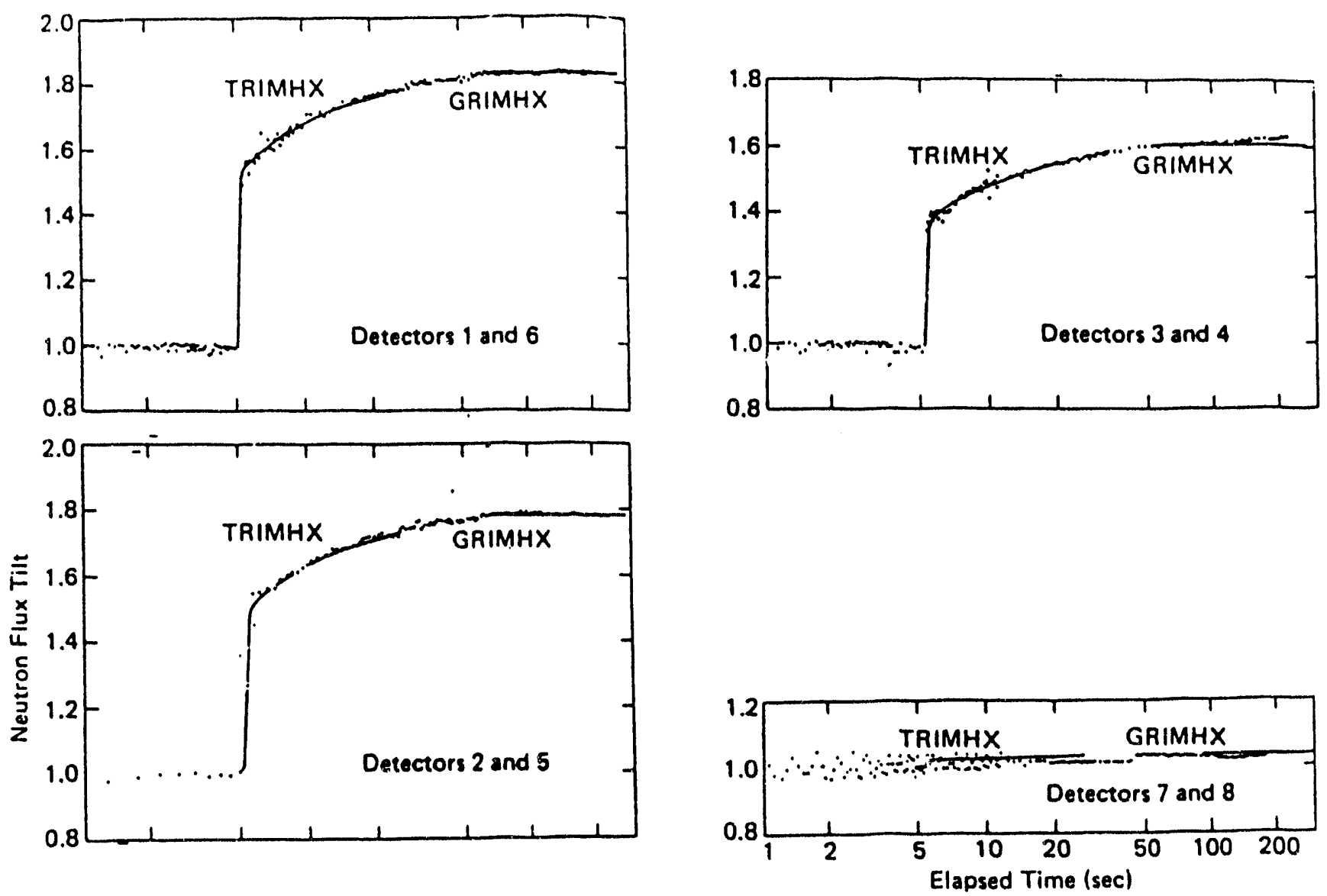

Overall, the tilt between the detector pairs resulting from the reactivity insertion has been well represented by TRIMHX/GRIMHX calculations. For Experiment \#1, the largest discrepancy $(\sim 4 \%)$ of the outer detector pair (1 and 4) flux tilt is due to the interstitial locations of the detectors. Since there is a strong variation of flux across the dummy sites and TRIMHX edits the product of cell flux and volume instead of the local value of the interstitial space, large discrepancy at this location is expected. For Experiment \#2, since there is no interstitial position of the detectors but all detectors were placed in the selected fuel cells, the agreement of the measured and calculated values are excellent. 


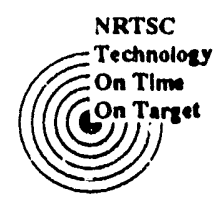

Verification, Validation, and Benmarking

WS R C - T R-92.044

Report for TRIMHX (U)

March, 1992

Page 19 of 47

\section{VI.2 THREE-DIMENSIONAL EXPERIMENTS}

\section{3-D Experiment \#1}

This is a center perturbation problem in which the transient was initiated by the insertion of three perturbation rods simultaneously into the three dry lithium-aluminum thimbles at the radial center of the reactor core. Each perturbation rod contained a column of $235 \mathrm{U}$ slugs in the bottom and a column of lithium slugs in the top. The induced transient flux shapes were distorted axially and radially but retained azimuthal symmetry. In this experiment, the space-time effects of the delayed neutron holdback was relatively small as shown by the small difference between tilts at the end of rod insertion ( $~ 5.1$ seconds) and the asymptotic tilts.

Figures 6.7 show the experiment geometry. Figures 6.8, 6.9, and 6.10 show the measured and calculated values of axial, radial, and diagonal flux tilts.

\section{Figure 6.7a: Face map of reactor core.}

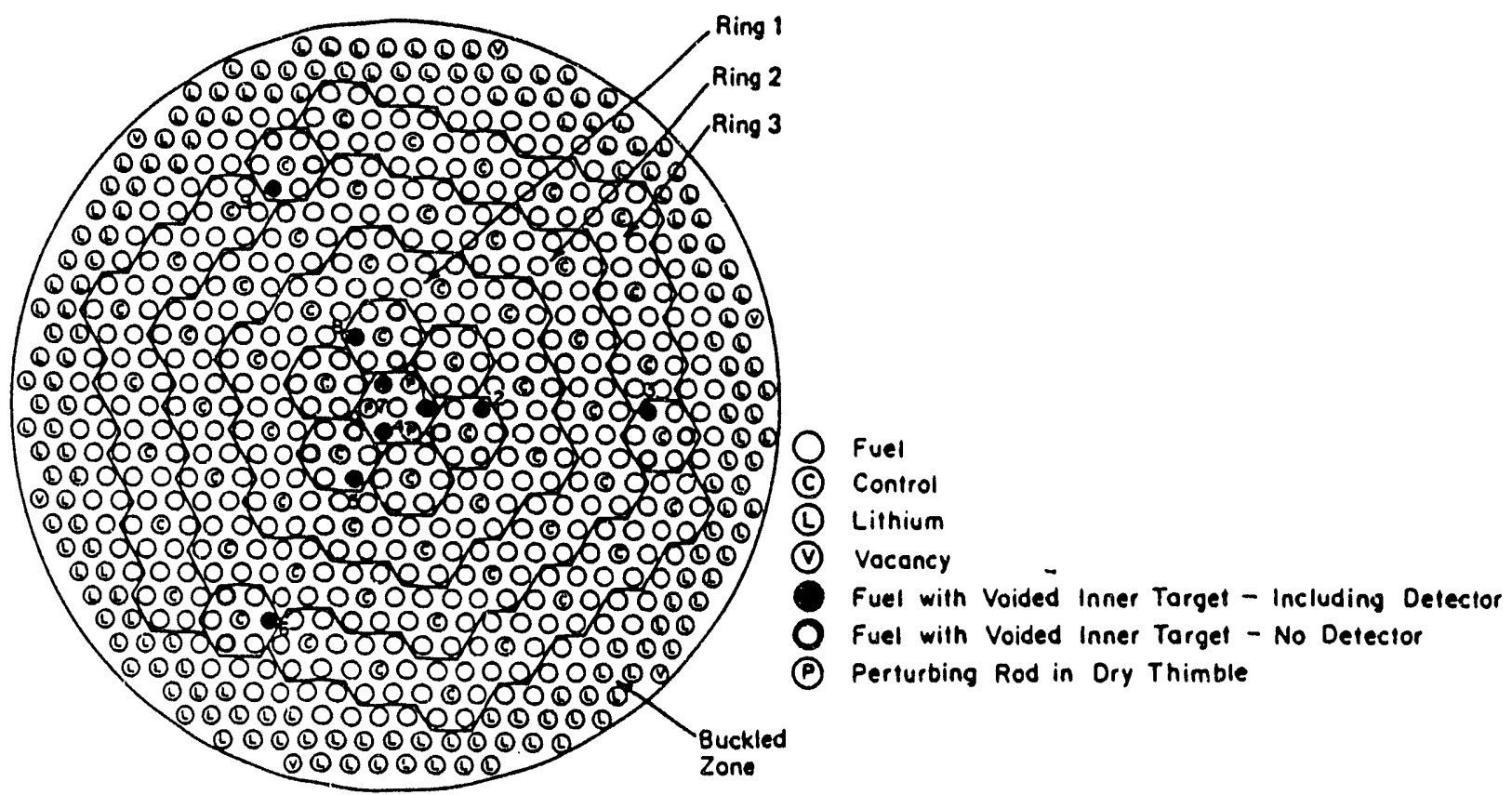


Figure 6.7b: Axial construction and layout of reactor core.

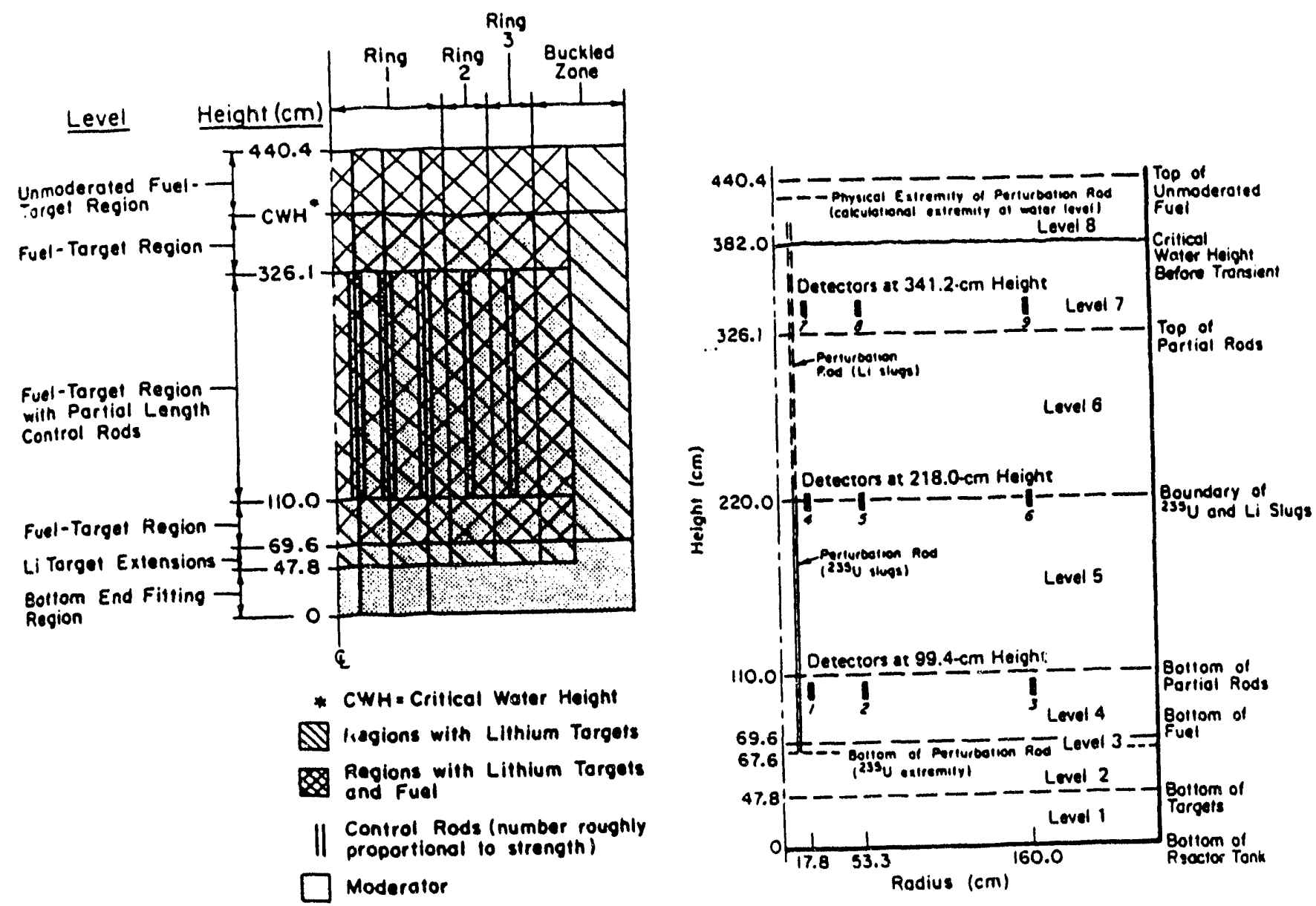


Figure 6.8: Measured and calculated axial flux tilts from Exp\#1.
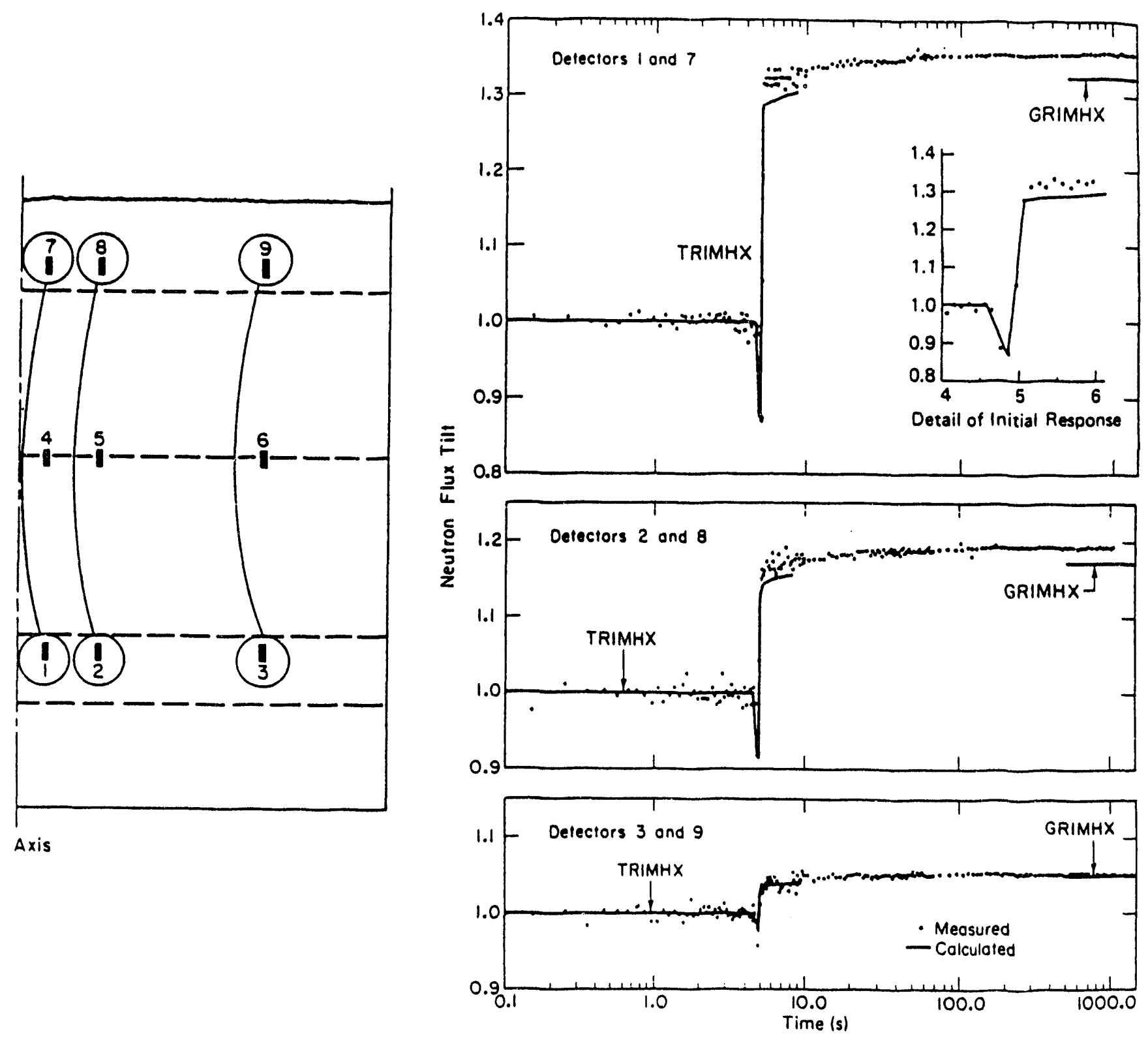


\section{Figure 6.9: Measured and calculated radial flux tilts from} Exp\#1.
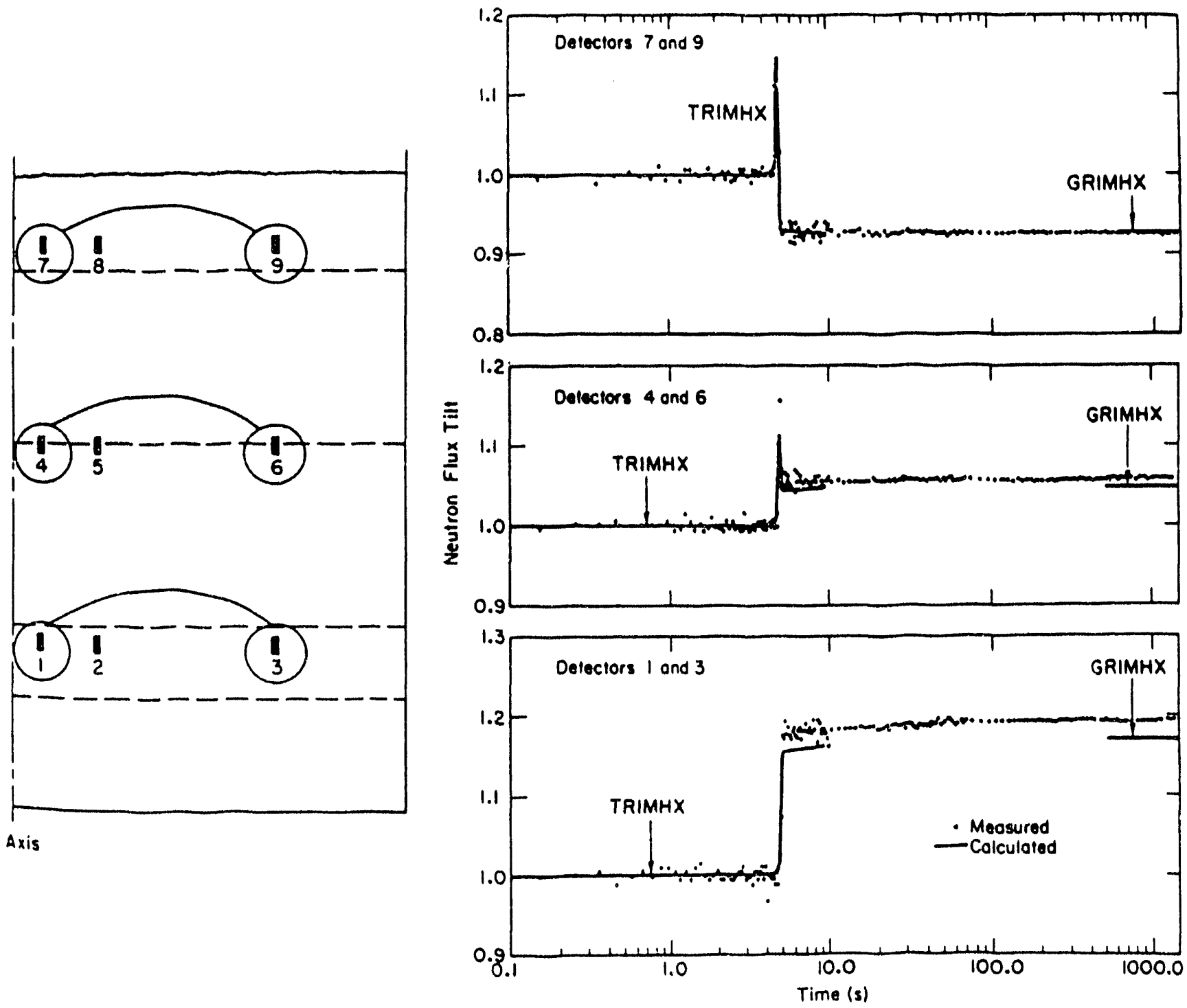


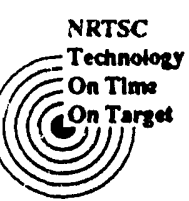

Verification, Validation, and Benmarking

WSR C-TR-92.344

Beport for TRIMHX (U)

March, :992

Page 23 of 47

Figure 6.10: Measured and calculated diagunal flux tilts from Exp\#1.
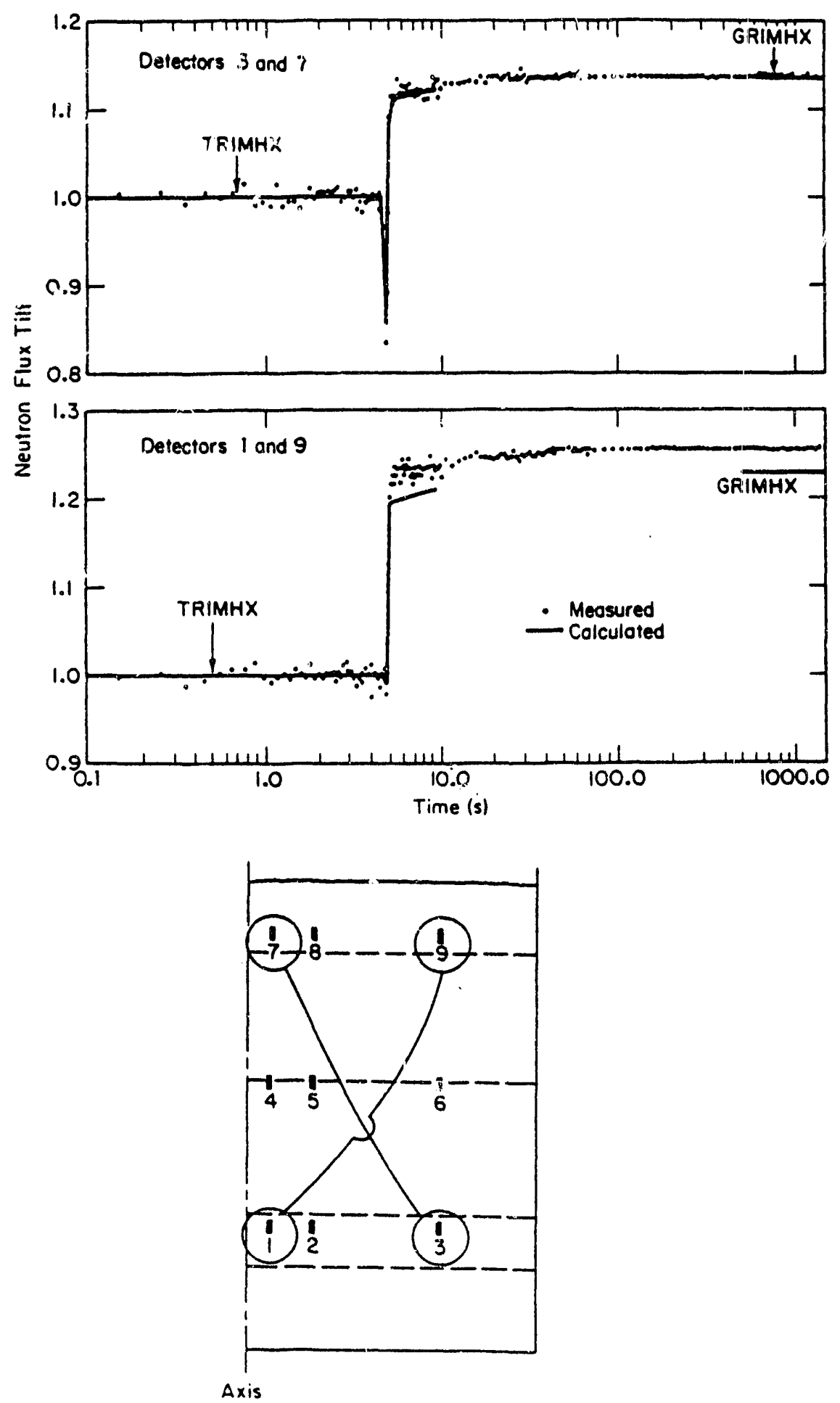


\section{3-D Experiment \#2}

This is an off-center perturbation problem in which the transient was initiated by the drop of six perturbation rods simultaneously into the six dry lithium-aluminum thimbles. Each perturbation rod contained a column of $235 \mathrm{U}$-bearing slugs in the bottom half of the rod. The induced transient flux shapes were distorted axially, radially, and azimuthally. In this experiment, the space-time effects of the delayed neutron holdback was most pronounced in the radial and azimuthal directions, but again relatively small in the axial tilts.

Figures 6.11 show the experiment geometry. Figures $6.12,6.13$, and 6.14 show the measured and calculated values of axial, radial, and diagonal flux tilts.

Figure 6.11a: Axial layout.

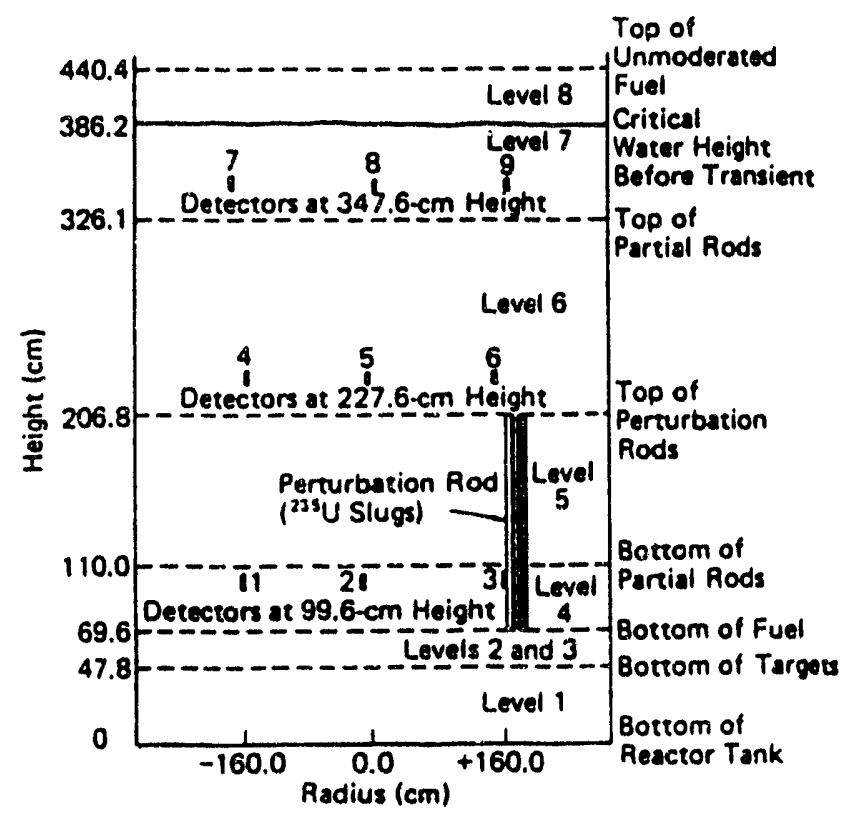


Figure 6.11b: Face map of reactor core.

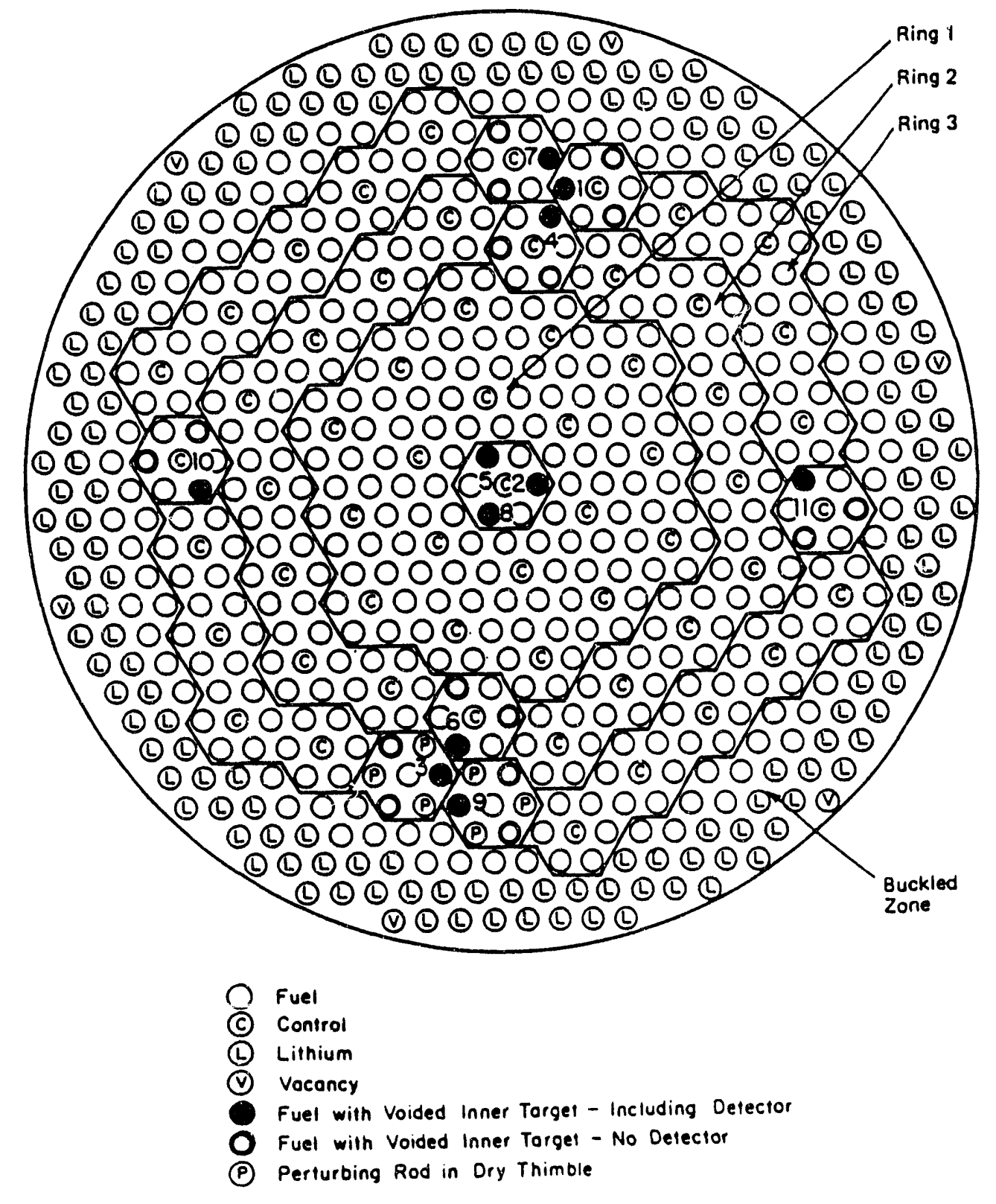


Figure 6.12: Measured and calculated axial flux tilts from Exp\#2.
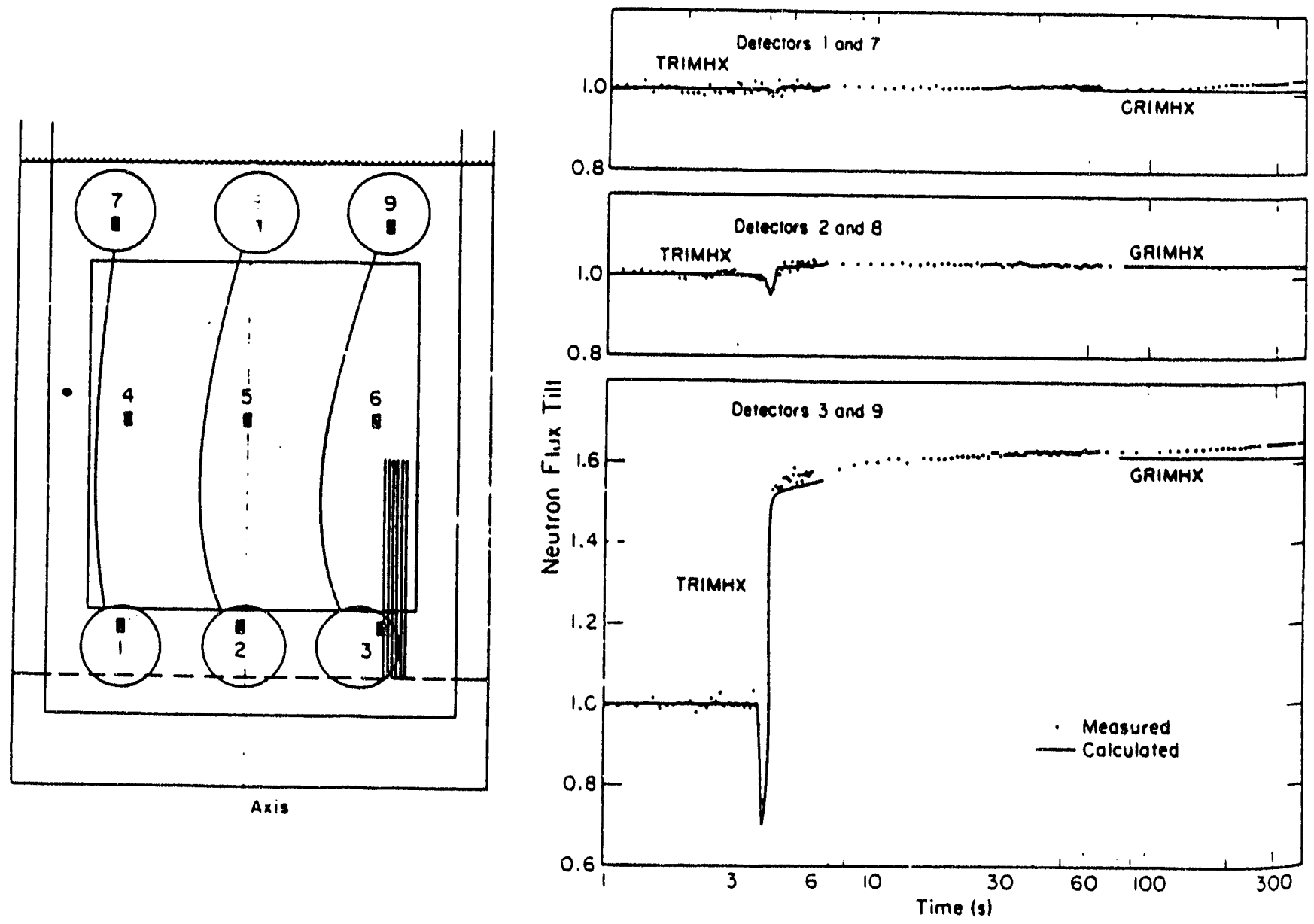
Verification, Validation, and Benmarking

Figure 6.13: Measured and calculated radial flux tilts from Exp\#2.
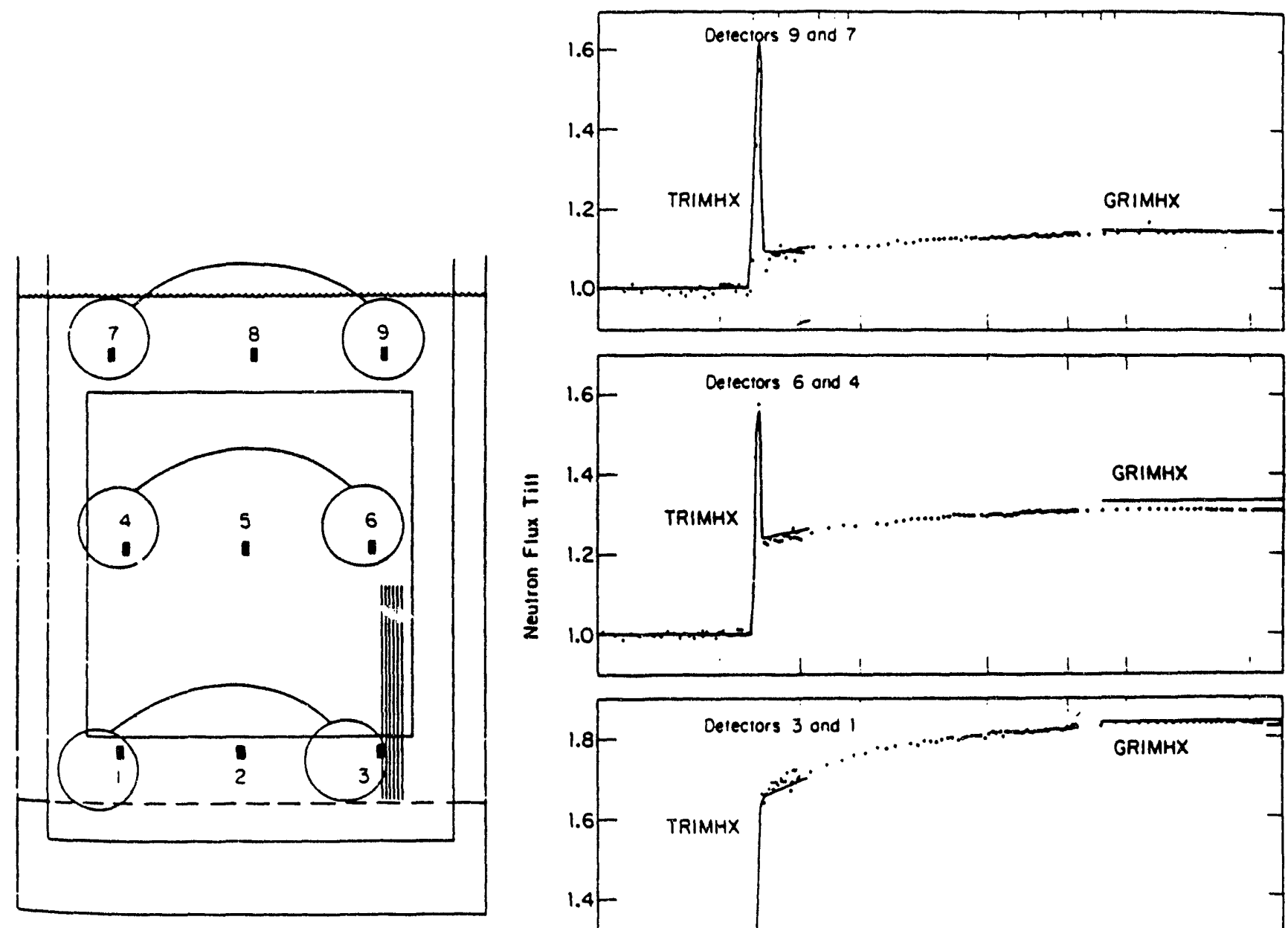

Axis

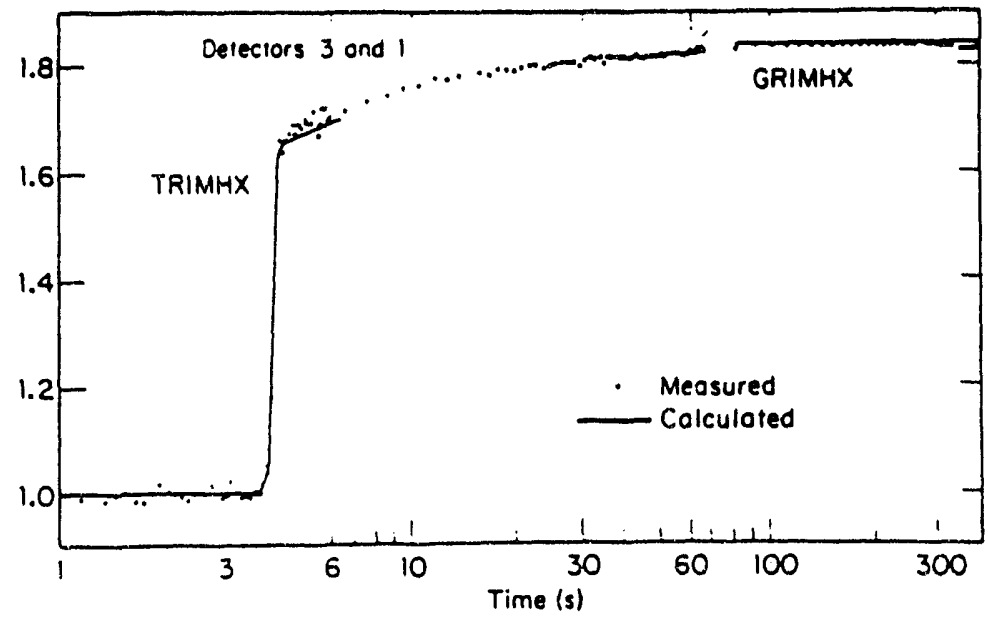


NRTSC

Technology

Con Tim

Verification, Validation, and Benmarking

WSR CT R-92.044

March, 1992

Report for TRIMHX (U)

Page 28 of 47

Figure 6.14: Measured and calculated diagonal flux tilts from Exp\#2.
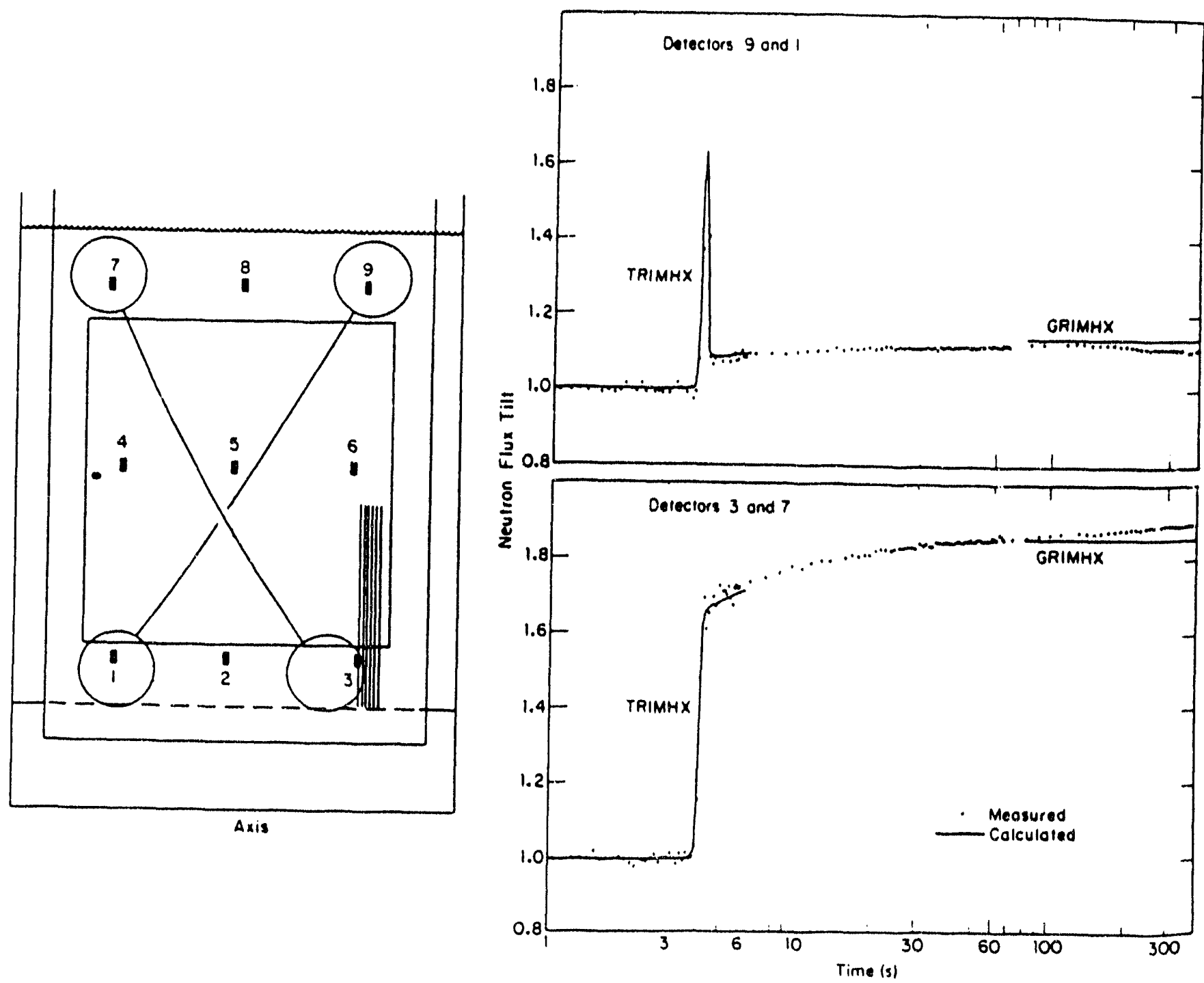


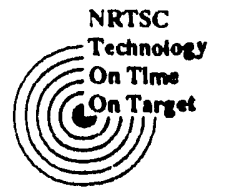

Verification, Validation, and Benmarking

WSR C - T R.92.044

Report for TRIMHX (U)

March, 1992

Page 29 of 47

\section{$\underline{\text { 3-D Experiment \#3 }}$}

This is a control rod withdrawal problem in which the experiment geometry is same as for Experiment \#1. The transient was initiated by the simultaneous withdrawal of one full length cadmium rod from each control rod assembly in the central region at a rate of $3.05 \mathrm{~cm} / \mathrm{s}$. The induced transient flux shapes were distorted axially and radially but retained azimuthal symmetry. In this experiment, the space-time effects of the delayed neutron holdback was relatively small due to the slow rate of withdrawal.

Figure 6.15 shows the experiment geometry. Figures $6.16,6.17$, and 6.18 show the measured and calculated values of axial, radial, and diagonal flux tilts.

Figure 6.15: Geometry of Experiment\#3.

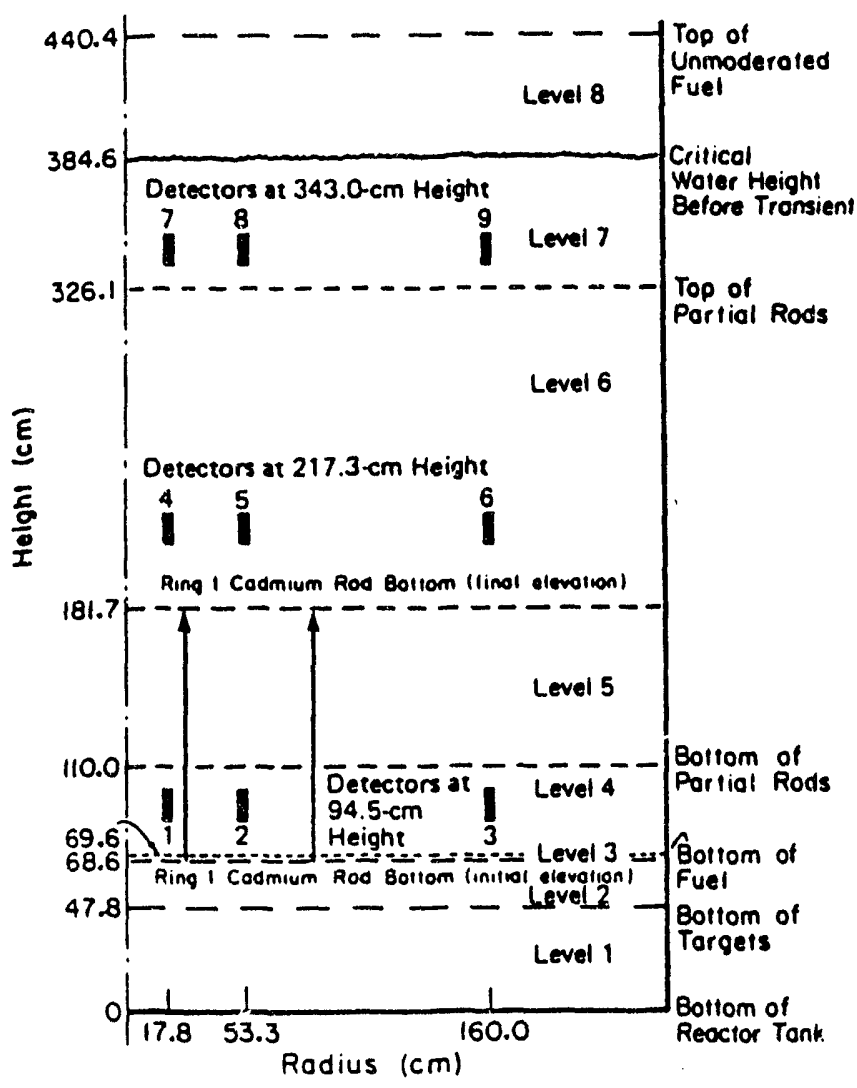


Figure 6.16: Measured and calculated axial flux tilts from Exp\#3.

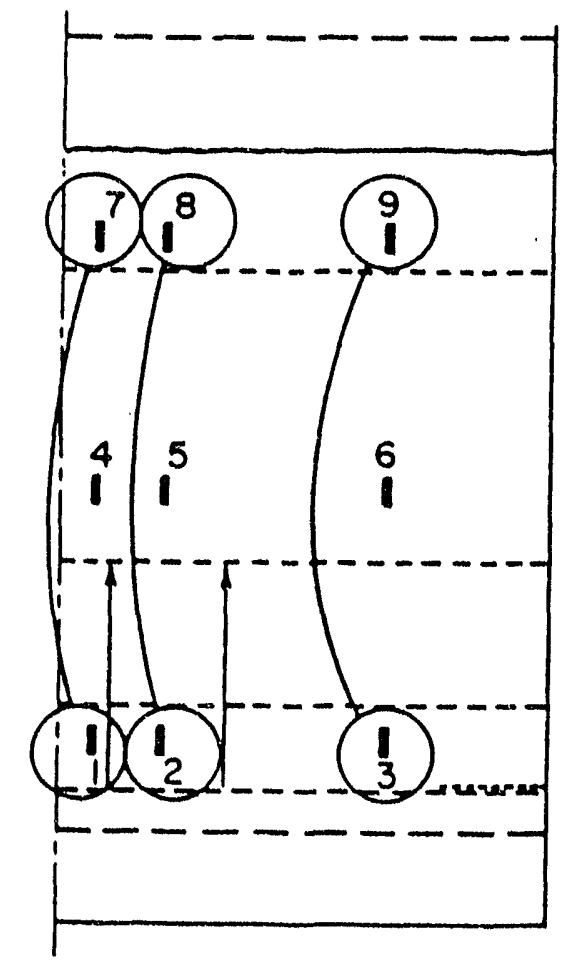

Axis

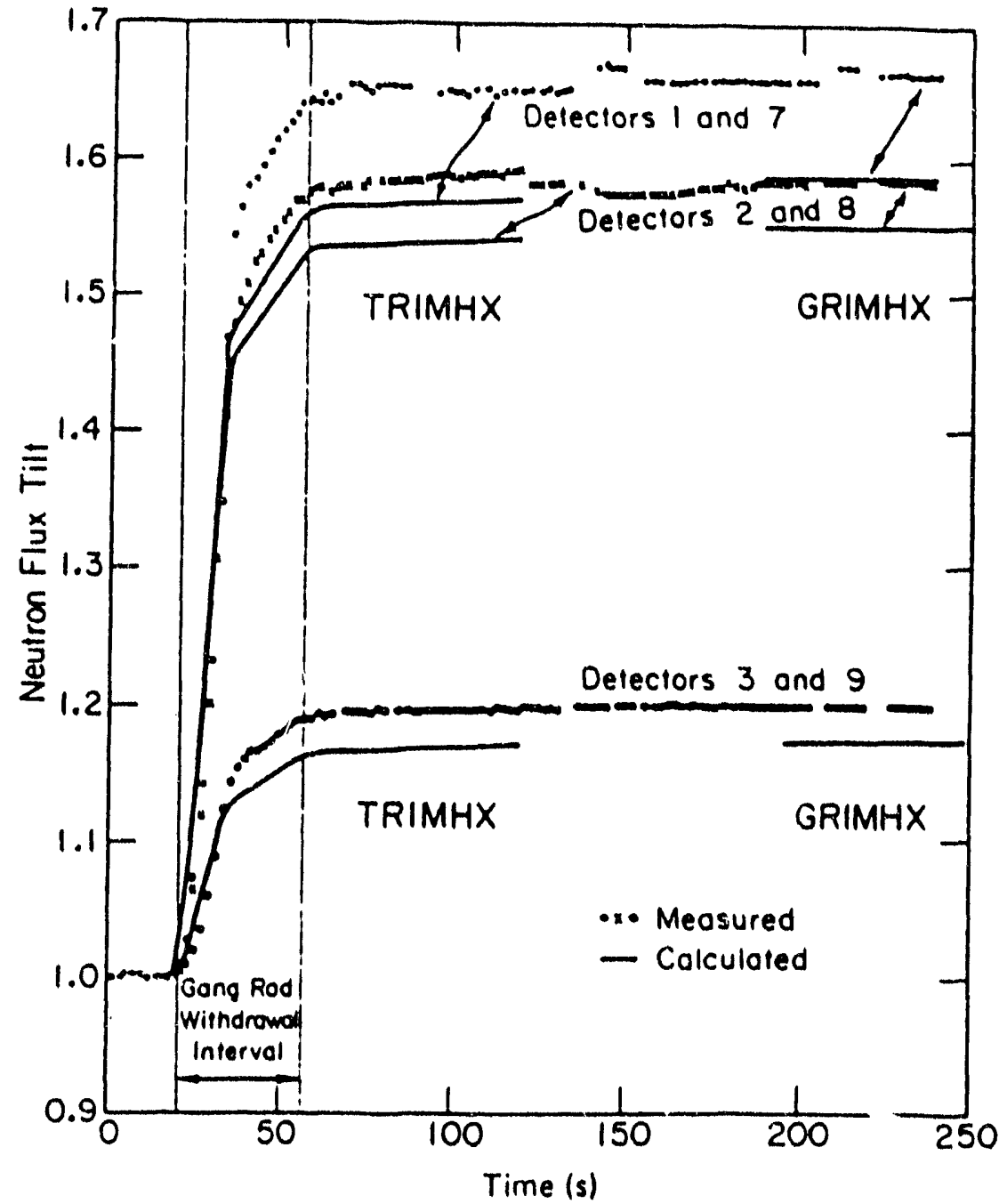


Verification, Validation, and Benmarking March, 1992

Report for TRIMHX (U)

Page 31 of 47

Figure 6.17: Measured and calculated radial flux tilts from Exp\#3.

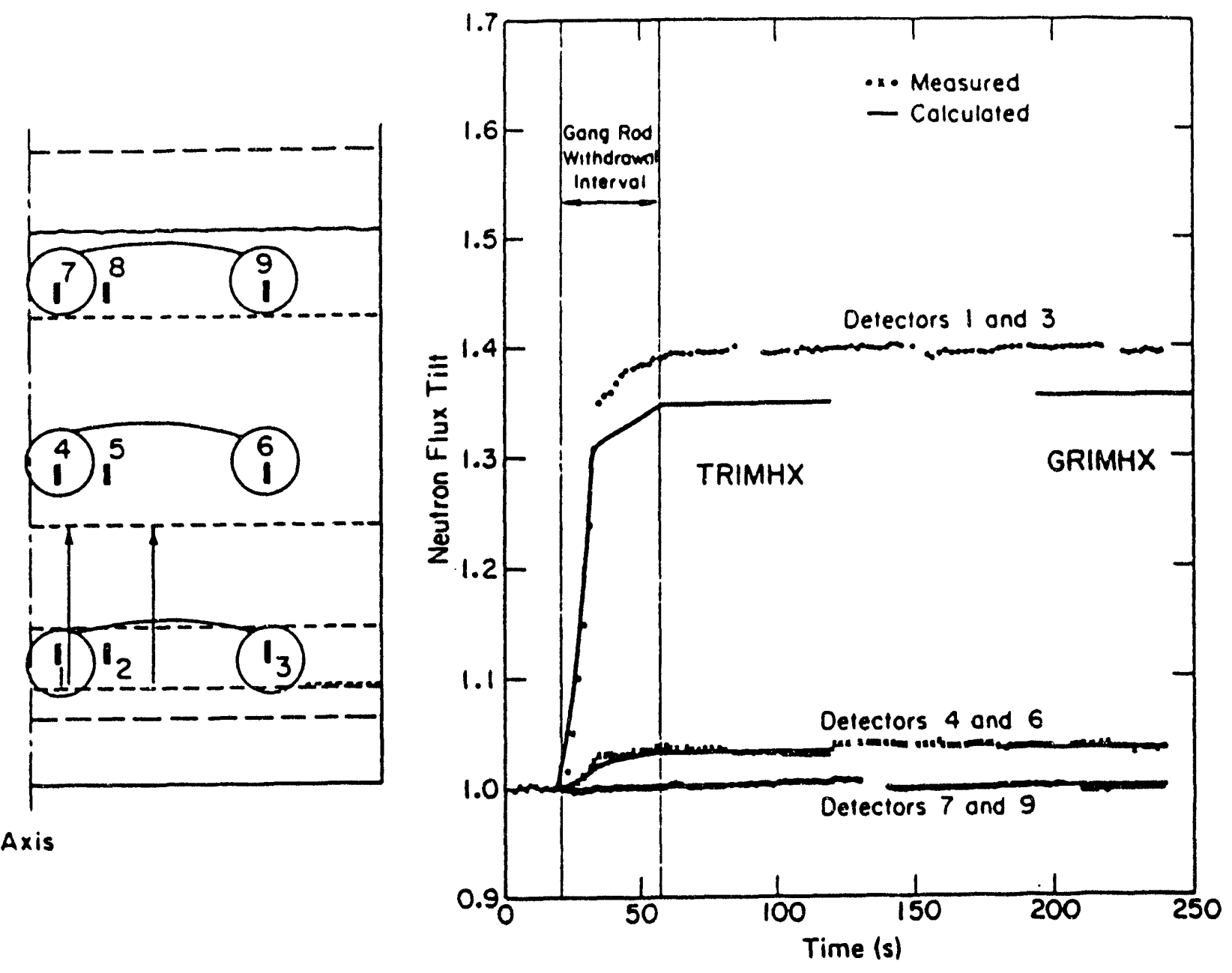


Figure 6.18: Measured and calculated diagonal flux tilts from Exp\#3.
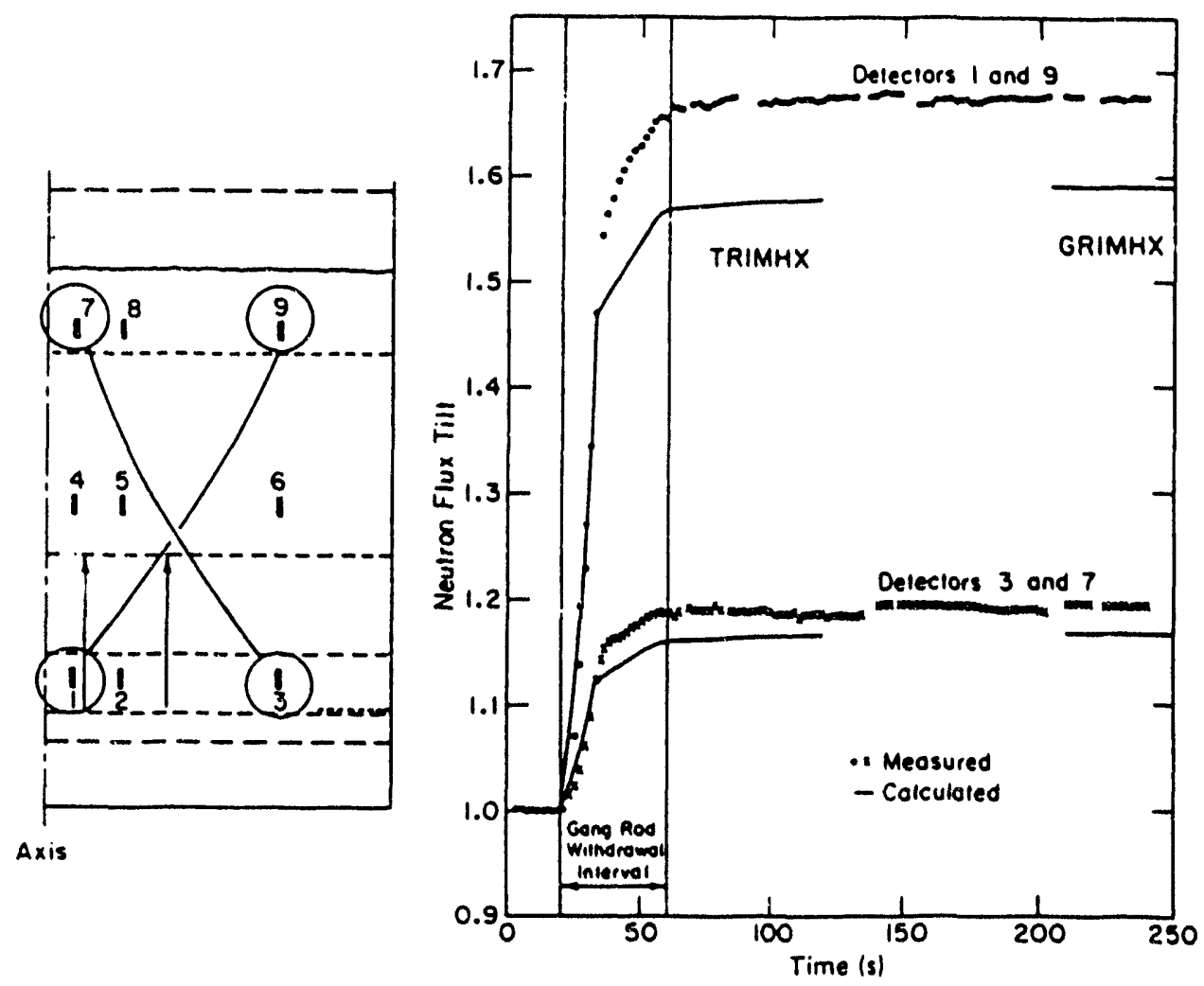

Due to the cost of computing time, TRIMHX was used to determine the calculated flux tilt up to $90 \%$ of the asymptotic value and GRIMHX was used to determine flux tilt at the asymptotic value. The results from these experiments show that measured tilts are well represented by the TRIMHX calculations. The influence of delayed neutron holdback in the tilts was calculated accurately. The maximum discrepancy between calculated and measured tilts was $2.3 \%$ in Experiment \#1, 2.4\% in Experiment \#2, and 4.8\% in Experiment \#3. In all comparisons, the tilt discrepancy was largest when a detector close to a region of positive reactivity insertion was involved. 


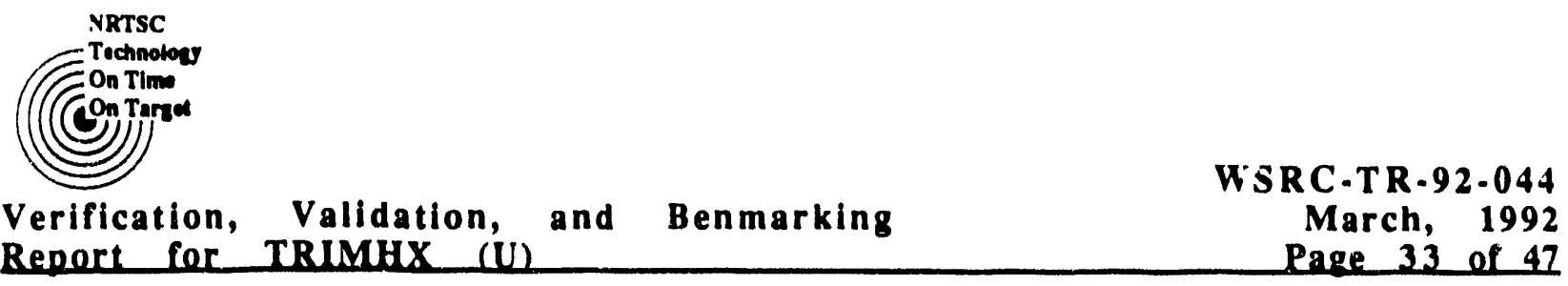

\section{Adiabatic Model Test Problem}

This test problem was performed by W. E. Graves in 1988 to test the adiabatic approximation in case of fast scram against the TRIMHX results ${ }^{11}$. During the perturbation, diffusion parameters at desired time values were calculated, and an adiabatic approximation model used the static reactor code GRIMHX to calculate the values of $k_{e}$ and used the point kinetic code AA312 to calculate the equivalent reactor powers at these times. Since this adiabatic model assumes the equilibrium of delayed neutron precursors at all times, the computed flux shape changes are expected to be a little larger than would be computed by a space-time code TRIMHX in which the delayed neutron holdback is computed.

The test problem was a two dimensional problem in which the thermal absorption cross sections in three perturbed regions were linearly increased in $50 \mathrm{msec}$. The calculations were performed for each $5 \mathrm{msec}$ step. Both the GRIMHX and TRIMHX used one point per hex and coarse mesh finite difference option.

The results of TRIMHX and adiabatic approximation are given in Tables 7.1-7.5. The maximum discrepancies between the two methods happened at the end of the perturbation and less than $1 \%$. Detail of the calculations and the input data are given in Reference 11.

Table 7.1: Relative Total Reactor Power

\begin{tabular}{llllll}
\hline $\begin{array}{l}\text { Time } \\
\text { (sec) }\end{array}$ & TRIMHX & Adia. Appro. & Time & TRIMHX & Adia. Appro. \\
0.05 & 1.0000 & 1.0000 & 0.06 & 0.9856 & 0.9899 \\
0.07 & 0.9596 & 0.9658 & 0.08 & 0.9281 & 0.9352 \\
0.09 & 0.8952 & 0.9026 & 0.10 & 0.8630 & 0.8704 \\
0.20 & 0.8096 & 0.8094 & 0.30 & 0.8006 & 0.8035 \\
0.40 & 0.7953 & 0.7982 & 0.50 & 0.7905 & 0.7934 \\
1.00 & 0.7704 & 0.7732 & 2.00 & 0.7407 & 0.7424 \\
3.00 & 0.7161 & 0.7175 & 4.00 & 0.6945 & 0.6958 \\
5.00 & 0.6753 & 0.6764 & & & \\
\hline
\end{tabular}


Table 7.2: Relative Position 1 (central hex) Power

\begin{tabular}{llllll}
\hline $\begin{array}{l}\text { Time } \\
\text { (sec) }\end{array}$ & TRIMHX & Adia. Appro & Time & TRIMHX & Adia. Appro. \\
\hline 0.05 & 1.0000 & 1.0000 & 0.06 & 0.9909 & 0.9979 \\
0.07 & 0.9707 & 0.9808 & 0.08 & 0.9445 & 0.9564 \\
0.09 & 0.9163 & 0.9292 & 0.10 & 0.8883 & 0.9013 \\
0.20 & 0.8350 & 0.8381 & 0.30 & 0.8260 & 0.8320 \\
0.40 & 0.8206 & 0.8265 & 0.50 & 0.8157 & 0.8216 \\
1.00 & 0.7952 & 0.8007 & 2.00 & 0.7649 & 0.7688 \\
3.00 & 0.7396 & 0.7430 & 4.00 & 0.7176 & 0.7205 \\
5.00 & 0.6978 & 0.7004 & & & \\
\hline
\end{tabular}

Table 7.3: Relative Position 2 (far from perturbation) Power

\begin{tabular}{llllll}
\hline $\begin{array}{l}\text { Time } \\
\text { (sec) }\end{array}$ & TRIMHX & Adia. App 0. & Time & TRIMHX & Adia. Appro. \\
0.05 & 1.0000 & 1.0000 & 0.06 & 0.9916 & 0.9981 \\
0.07 & 0.9721 & 0.9811 & 0.08 & 0.9464 & 0.9566 \\
0.09 & 0.9184 & 0.9297 & 0.10 & 0.8905 & 0.9019 \\
0.20 & 0.8361 & 0.8387 & 0.30 & 0.8269 & 0.8326 \\
0.40 & 0.8214 & 0.8271 & 0.50 & 0.8165 & 0.8221 \\
1.00 & 0.7960 & 0.8012 & 2.00 & 0.7656 & 0.7693 \\
3.00 & 0.7404 & 0.7435 & 4.00 & 0.7183 & 0.7210 \\
5.00 & 0.6985 & 0.7009 & & & \\
\hline
\end{tabular}




\section{Table 7.4: Relative Position 3 (few lattice pitches from perturbation) Power}

\begin{tabular}{llllll}
\hline $\begin{array}{l}\text { Time } \\
\text { (sec) }\end{array}$ & TRIMHX & Adia. Appro. & Time & TRIMHX & Adia. Appro. \\
\hline 0.05 & 1.0000 & 1.0000 & 0.06 & 0.9808 & 0.9827 \\
0.07 & 0.9490 & 0.9518 & 0.08 & 0.9124 & 0.9153 \\
0.09 & 0.8750 & 0.8777 & 0.10 & 0.8390 & 0.8413 \\
0.20 & 0.7859 & 0.7823 & 0.30 & 0.7770 & 0.7766 \\
0.40 & 0.7718 & 0.7715 & 0.50 & 0.7670 & 0.7668 \\
1.00 & 0.7472 & 0.7473 & 2.00 & 0.7181 & 0.7175 \\
3.00 & 0.6940 & 0.6935 & 4.00 & 0.6730 & 0.6725 \\
5.00 & 0.6541 & 0.6538 & & & \\
\hline
\end{tabular}

Table 7.5: Relative Position 4 (next to perturbation) Power

\begin{tabular}{llllll}
\hline $\begin{array}{l}\text { Time } \\
\text { (sec) }\end{array}$ & TRIMHX & Adia. Appro. & Time & TRIMHX & Adia. Appro. \\
\hline 0.05 & 1.0000 & 1.0000 & 0.06 & 0.9673 & 0.9672 \\
0.07 & 0.9224 & 0.9232 & 0.08 & 0.8744 & 0.8749 \\
0.09 & 0.8273 & 0.8271 & 0.10 & 0.7831 & 0.7820 \\
0.20 & 0.7328 & 0.7272 & 0.30 & 0.7246 & 0.7219 \\
0.40 & 0.7196 & 0.7171 & 0.50 & 0.7151 & 0.7128 \\
1.00 & 0.6965 & 0.6947 & 2.00 & 0.6691 & 0.6670 \\
3.00 & 0.6464 & 0.6446 & 4.00 & 0.6267 & 0.6251 \\
5.00 & 0.6091 & 0.6077 & & & \\
\hline
\end{tabular}


Verification, Validation, and Benmarking

WSRC.-TR-92.044

Bepert for TRIMHX (U)

March, 1992

Page 36 of 47

\section{Comparisons with Other Codes}

\section{VIII.1 COMPARISON WITH DIF3D}

In 1991, T. A. Taiwo and H. S. Khalil at Reactor Analysis Division of Argonne National Laboratory tested the performance of the Hex- $Z$ geometry option of the Nodal kinetics DIF3D code by comparing the DIF3D results with the TRIMHX results ${ }^{13}$. Test problem 3 in section IV. 3 and test problem 2 in section VI.1 were used for this testing and the results show a very good agreement between the two codes. Figure 8.1 shows the results of test problem 3 in Section IV.3 for case of 87 cents reactivity insertion and Figure 8.2 shows the flux tilts of test problem 2 in Section VI.1. Details of the comparision can be found in Reference 13.

Figure 8.1: Relative Thermal Flux at Central Assembly Midplane vs. Time of TRIMHX and DIF3D

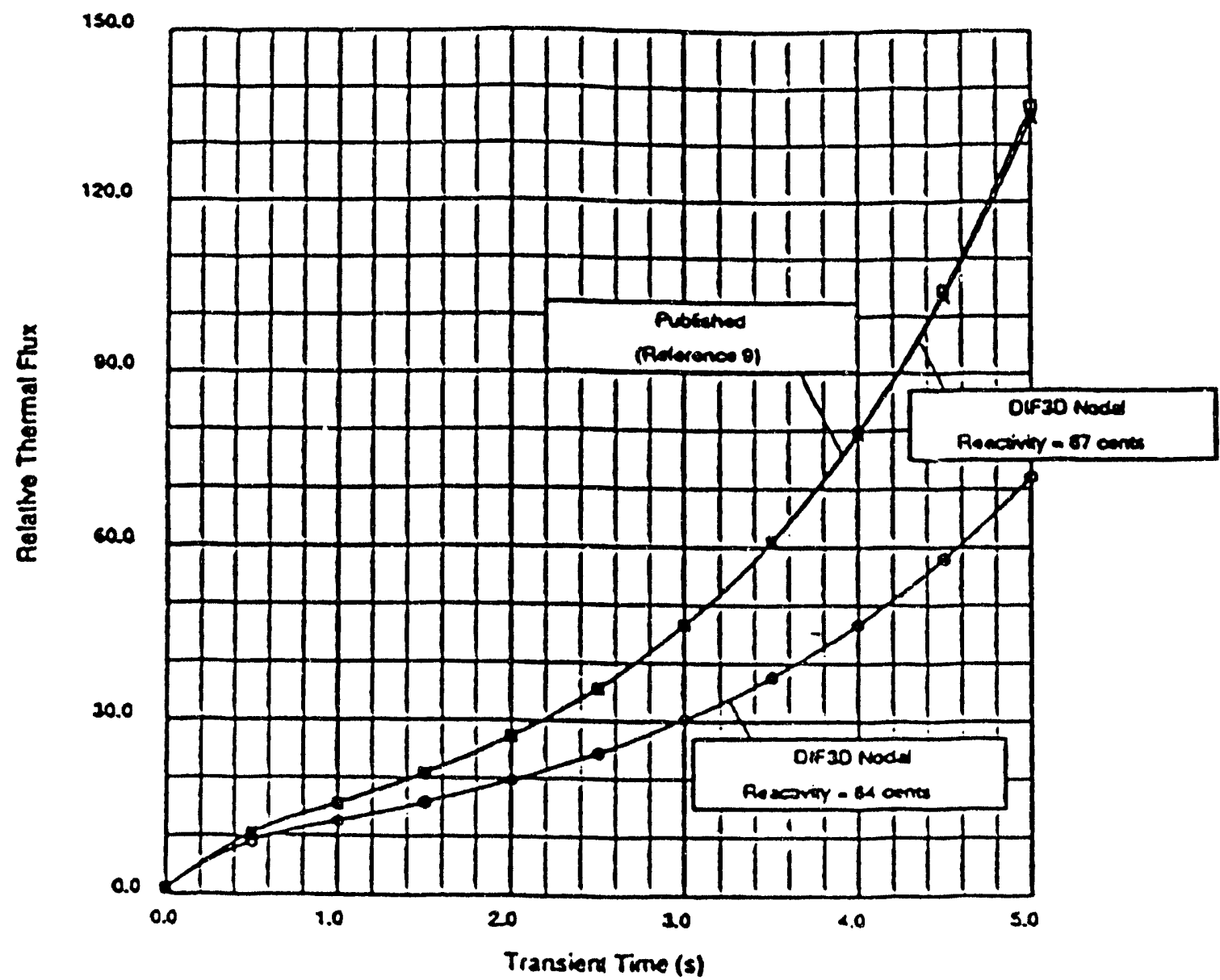


Verification, Validation, and Benmarkii,o

\section{Figure 8.2: Measured and Calculate Flux Tilts}
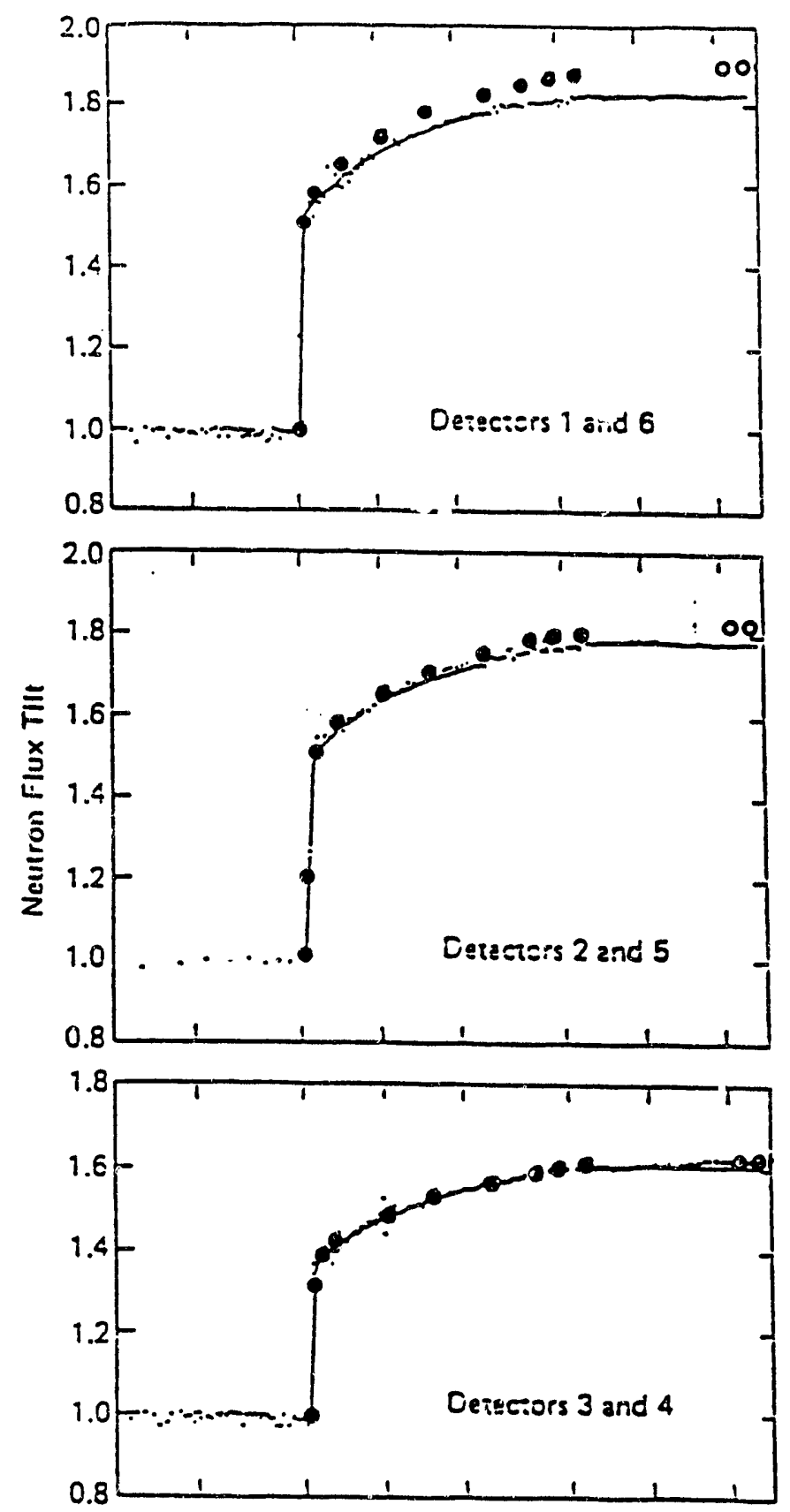

Legend

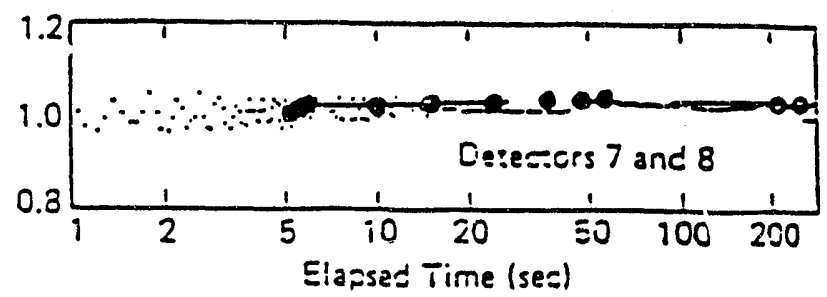

.... Measured

- TRIMHX, Ret. 8

- DIF3D-Nodal

OO DIF3D-Nodal (Asymptotic) 


\section{2 COMPARISON WITH DIF3D AND FX2-TH}

A two-dimensional problem in the $T$. A. Taiwo report ${ }^{13}$ was used to compare the TRIMHX results to the nodal DIF3D and the finite-difference quasi-static FX2-TH ${ }^{14}$ results. The original problem configuration is shown in Figure 8.3 and the problem data are listed in Tables 8.1 to 8.3. Since TRIMHX requires closed patch geometry, the problem configuration in TRIMHX run is not exactly identical to the problem configuration in DIF3D and FX2-TH runs; they are different at the reactor core boundary. Figure 8.4 shows the TRIMHX problem configuration and Figure 8.5 shows relative core power versus time from the TRIMHX, DIF3D, and FX2-TH solutions.

\section{Table 8.1: Cross Section Data}

\begin{tabular}{|c|c|c|c|c|c|c|}
\hline Comp & Group & Diffusion & Capure & Fission & $\mathrm{Nu} * \mathrm{Fission}$ & Scattering \\
\hline 1 & $\begin{array}{l}1 \\
2\end{array}$ & $\begin{array}{l}1.38250 \\
0.89752\end{array}$ & $\begin{array}{l}1.63052 E-3 \\
1.25423 E-2\end{array}$ & $\begin{array}{l}9.30113 E-4 \\
9.51810 E-3\end{array}$ & $\begin{array}{l}2.26216 E \cdot-3 \\
2.30623 E-2\end{array}$ & $8.16457 \mathrm{E}-3$ \\
\hline 2 & $\begin{array}{l}1 \\
2\end{array}$ & $\begin{array}{l}1.38255 \\
0.89749\end{array}$ & $\begin{array}{l}1.65429 \mathrm{E}-3 \\
1.27782 \mathrm{E}-2\end{array}$ & $\begin{array}{l}9.15899 E-4 \\
9.36233 E-3\end{array}$ & $\begin{array}{l}2.22750 \mathrm{E}-3 \\
2.26849 \mathrm{E}-2\end{array}$ & $8.22378 E-3$ \\
\hline 3 & $\begin{array}{l}1 \\
2\end{array}$ & $\begin{array}{l}1.37442 \\
0.88837\end{array}$ & $\begin{array}{l}1.27299 E-3 \\
8.24602 E-3\end{array}$ & $\begin{array}{l}8.80841 E-4 \\
8.45594 E-3\end{array}$ & $\begin{array}{l}2.14281 E-3 \\
2.04887 E-2\end{array}$ & $8.08816 E-3$ \\
\hline 4 & $\begin{array}{l}1 \\
2\end{array}$ & $\begin{array}{l}1.38139 \\
0.90367\end{array}$ & $\begin{array}{l}1.43233 \mathrm{E}-3 \\
1.06673 \mathrm{E} \cdot 2\end{array}$ & $\begin{array}{l}9.84814 \mathrm{E}-4 \\
1.09869 \mathrm{E}-2\end{array}$ & $\begin{array}{l}2.39469 E-3 \\
2.66211 L-2\end{array}$ & $7.76568 E-3$ \\
\hline 5 & $\begin{array}{l}1 \\
2\end{array}$ & $\begin{array}{l}1.30599 \\
0.85662\end{array}$ & $\begin{array}{l}2.74282 \mathrm{E}-4 \\
4.10254 \mathrm{E}-5\end{array}$ & & & $1.10975 \mathrm{E}-2$ \\
\hline 6 & $\begin{array}{l}1 \\
2\end{array}$ & $\begin{array}{l}1.29193 \\
0.81934\end{array}$ & $\begin{array}{l}1.44797 \mathrm{E}-6 \\
7.50003 \mathrm{E}-5\end{array}$ & & & $1.15582 \mathrm{E}-2$ \\
\hline 7 & $\begin{array}{l}1 \\
2\end{array}$ & $\begin{array}{l}1.06510 \\
0.32283\end{array}$ & $\begin{array}{l}1.85500 \mathrm{E}-3 \\
3.32600 \mathrm{E}-2\end{array}$ & & & $2.61980 \mathrm{E}-2$ \\
\hline
\end{tabular}




\section{Table 8.2: Delayed Neutron Data}

Family Number Delayed Neutron Fraction Decay Constant (1/sec)

$\begin{array}{ll}1 & 1.68000 \mathrm{E}-04 \\ 2 & 8.25700 \mathrm{E}-04 \\ 3 & 3.09920 \mathrm{E}-03 \\ 4 & 1.21030 \mathrm{E}-03 \\ 5 & 1.76570 \mathrm{E}-03 \\ 6 & 1.10900 \mathrm{E}-04\end{array}$

$3.87100 E-00$

$1.40000 \mathrm{E}-00$

3. $05800 \mathrm{E}-01$

$1.15000 \mathrm{E}-01$

$2.78100 \mathrm{E}-02$

$2.59800 E-03$

\section{Table 8.3: Additional Data}

Lattice Pitch $=17.18 \mathrm{~cm}(7.0$ inches $)$

Buckling $=2.753 \mathrm{E}-041 / \mathrm{cm}^{2}$

$\begin{array}{lcc}\text { Eission Spectrum: } & \frac{\text { Group } 1}{\text { Group } 2} \\ \text { Neutron Velocity: } & 1.0000 \mathrm{E}-00 & 0.0000 \mathrm{E}-00 \\ & 1.1286 \mathrm{E}+07 & 3.0806 \mathrm{E}+05\end{array}$

Transient: Thermal absorption cross section of composition 1 reduces $4.5 \%$ in 0.2 second. 


\section{Figure 8.3: FX2-TH and DIF3D Problem Configuration}
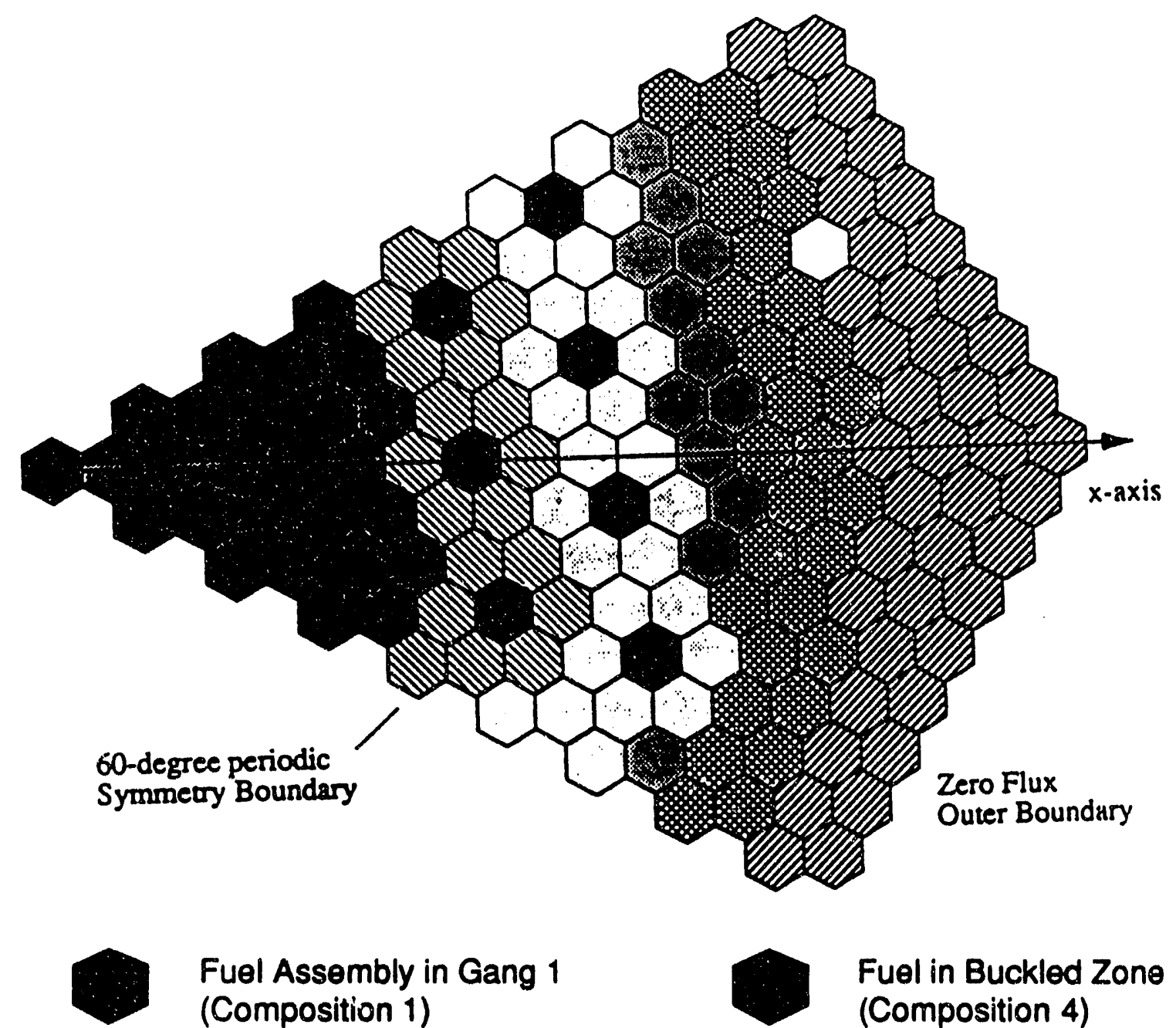

Fuel Assembly in Gang 1 (Composition 1)

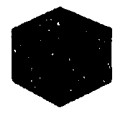

Fuel in Buckled Zone (Composition 4)

W

Fuel Assembly in Gang 2 (Composition 2)

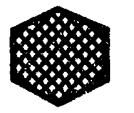

Lithium Target (Composition 5)<smiles>c1ccccc1</smiles>

Fuel Assembly in Gang 3 (Composition 3)<smiles>C1CCCCC1</smiles>

Vacancy

(Composition 6)

Control Assembly (Included in Composition 1, 2, 3) 


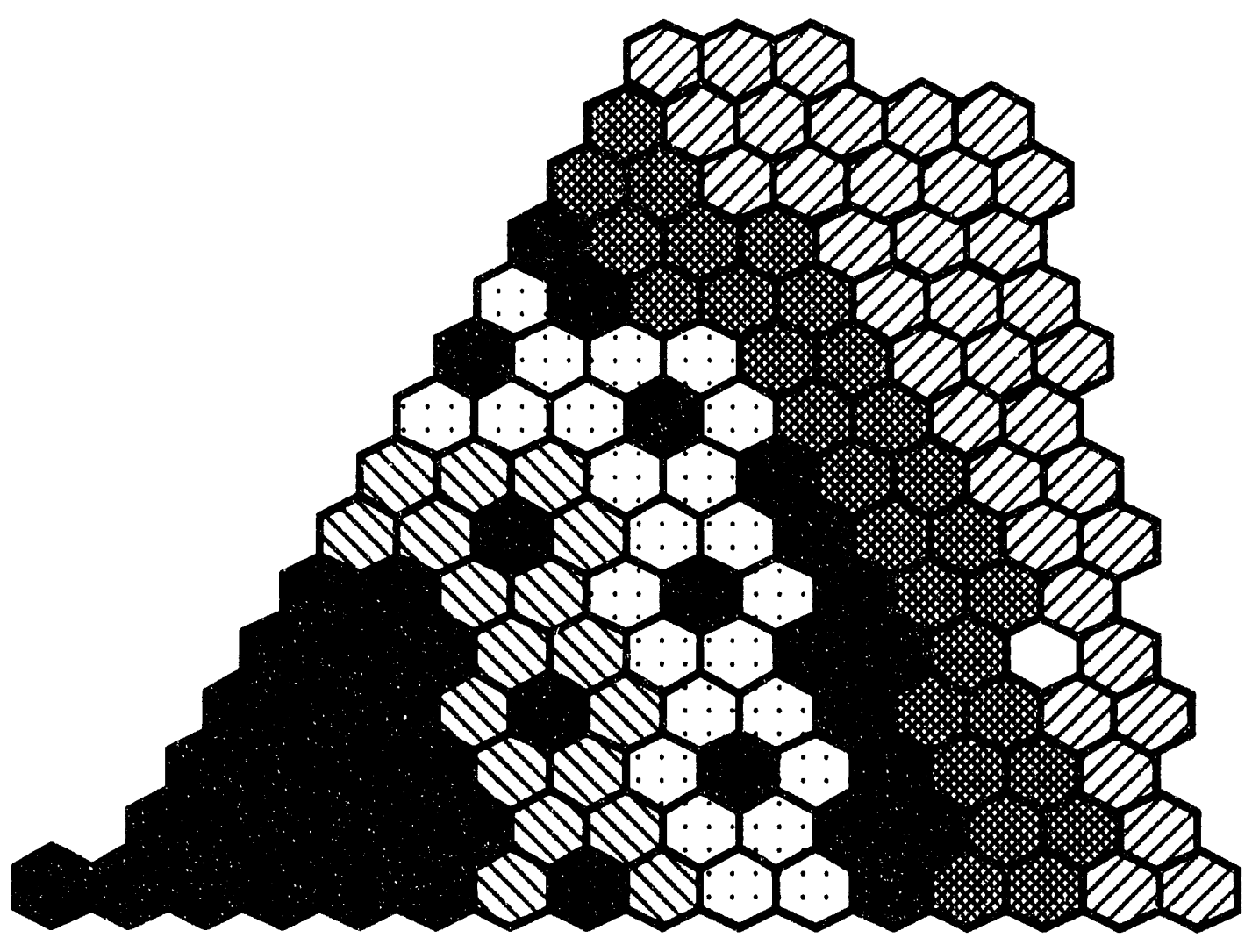

Fuel Assembly in Gang 1 (Composition 1)

Fuel Assembly in Gang 2 (Composition 2)<smiles>c1ccccc1</smiles>

Fuel Assembly in Gang 3 (Composition 3)

Control Assembly (Included in Composition 1, 2, 3)
Fuel in Buckled Zone (Composition 4)

Lithium Target

(Composition 5)

$\bigcirc \begin{aligned} & \text { Vacancy } \\ & \text { (Composition 6) }\end{aligned}$

$Q$ Core Exterior

(Composition 7) 
Figure 8.5: Core Power vs. Time

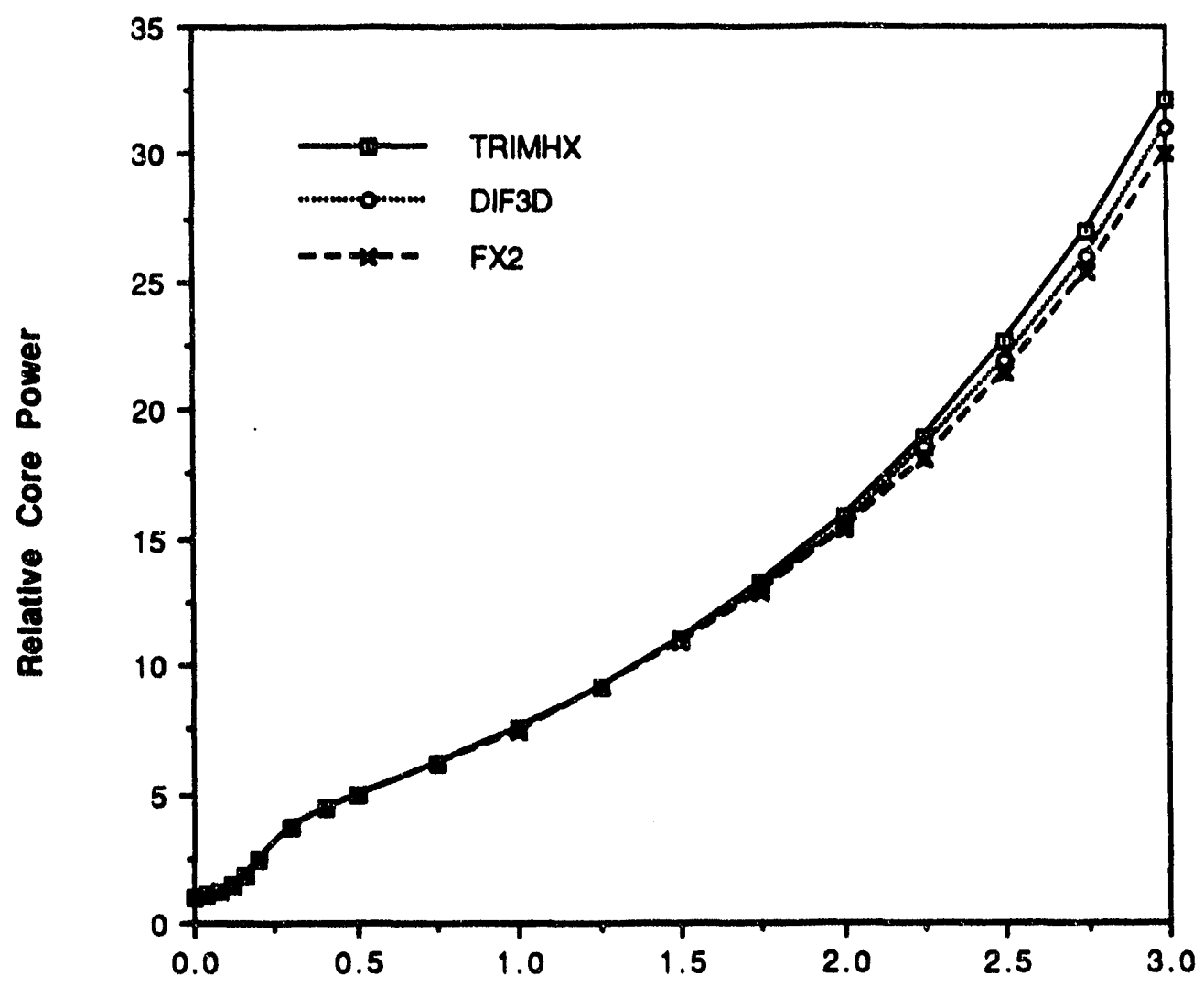

Time (soc.) 
Verification, Validation, and Benmarking

\section{Comparisons of Initial TRIMHX to GRIMHX Results}

In 1989, the two-dimensional HTGR benchmark problem of GRIMHX was run by both GRIMHX and TRIMHX codes on the IBM by E. F. Trumble to test the static calculations of TRIMHX ${ }^{8,15}$. The comparison results in Tables 9.1 and 9.2 show the excellent agreements in static calculations of the GRIMHX and TRIMHX codes. Details of the comparison can be found in Reference 15.

Table 9.1: keff of Static TRIMHX \& GRIMHX Calculations

\begin{tabular}{lll}
\hline Code & Normalization & keff \\
\hline GRIMHX & Power & 1.11320 \\
TRIMHX & Power & 1.11320 \\
GRIMHX & Production & 1.11320 \\
TRIMHX & Production & 1.11320 \\
\hline
\end{tabular}

Table 9.2: Fluxes in Center Hex of Static TRIMHX \& GRIMHX Calculations

\begin{tabular}{|c|c|c|c|c|}
\hline Group & $\begin{array}{c}\text { Power } \\
\text { GRIMHX }\end{array}$ & $\begin{array}{c}\text { Normalization } \\
\text { TRIMHX }\end{array}$ & $\begin{array}{l}\text { Production } \\
\text { GRIMHX } \\
\end{array}$ & $\begin{array}{r}\text { Normalization } \\
\text { TRIMHX }\end{array}$ \\
\hline $\begin{array}{l}1 \\
2 \\
3 \\
4\end{array}$ & $\begin{array}{l}1.788 \mathrm{E} 19 \\
4.071 \mathrm{E} 19 \\
5.495 \mathrm{E} 18 \\
2.008 \mathrm{E} 19\end{array}$ & $\begin{array}{l}1.787 \mathrm{E} 19 \\
4.062 \mathrm{E} 19 \\
5.487 \mathrm{E} 18 \\
2.006 \mathrm{E} 19\end{array}$ & $\begin{array}{l}1.418 \mathrm{E} 2 \\
3.228 \mathrm{E} 2 \\
4.357 \mathrm{E} 1 \\
1.592 \mathrm{E} 2\end{array}$ & $\begin{array}{l}1.417 \mathrm{E} 2 \\
3.223 \mathrm{E} 2 \\
4.351 \mathrm{E} 1 \\
1.590 \mathrm{E} 2\end{array}$ \\
\hline
\end{tabular}

The same HTGR problem was run for this report by T. T. Le for both J80 (new JOSHUA system ${ }^{16}$ ) versions of GRIMHX and TRIMHX on the VAX to test the initial calculations of the TRIMHX code and to verify the conversion of J70 (old JOSHUA system) TRIMHX to J80 TRIMHX. The comparison results in Tables 9.3 and 9.4 show the excellent agreements in static calculations of the J70 and J80 GRIMHX and TRIMHX codes. 
WSRC-T R.92.044

March, 1992

Page 44 of 47

Verification, Validation, and Benmarking Beport for TRIMHX (U)

Table 9.3: keff of Static TRIMHX \& GRIMHX Calculations

\begin{tabular}{lll}
\hline Code & Normalization & $k_{\text {eff }}$ \\
\hline GRIMHX & Power & 1.11320 \\
TRIMHX & Power & 1.11320 \\
GRIMHX & Production & 1.11320 \\
TRIMHX & Production & 1.11320 \\
\hline
\end{tabular}

Table 9.4: Fluxes in Center Hex of Static TRIMHX \& GRIMHX Calculations

\begin{tabular}{lrrrr}
\hline Group & $\begin{array}{c}\text { Power } \\
\text { GRIMHX }\end{array}$ & $\begin{array}{c}\text { Normalization } \\
\text { TRIMHX }\end{array}$ & $\begin{array}{c}\text { Production } \\
\text { GRIMHX }\end{array}$ & $\begin{array}{r}\text { Normalization } \\
\text { TRIMHX }\end{array}$ \\
& & & & \\
1 & $1.788 \mathrm{E} 19$ & $1.789 \mathrm{E} 19$ & $2.368 \mathrm{E} 2$ & $2.369 \mathrm{E} 2$ \\
2 & $4.072 \mathrm{E} 19$ & $4.072 \mathrm{E} 19$ & $5.392 \mathrm{E} 2$ & $5.392 \mathrm{E} 2$ \\
3 & $5.496 \mathrm{E} 18$ & $5.496 \mathrm{E} 18$ & $7.277 \mathrm{E} 1$ & $7.277 \mathrm{E} 1$ \\
4 & $2.008 \mathrm{E} 19$ & $2.008 \mathrm{E} 19$ & $2.659 \mathrm{E} 2$ & $2.659 \mathrm{E} 2$ \\
\hline
\end{tabular}

Another three-dimensional GRIMHX test problem was run for this report by T. T. Le. Again, the comparison results in Tables 9.5 and 9.6 show the excellent agreements in static calculations of the GRIMHX and TRIMHX codes.

Table 9.5: keff of Static TRIMHX \& GRIMHX Calculations

\begin{tabular}{llc}
\hline Code & Normalization & $k_{\text {eff }}$ \\
\hline GRIMHX & Power & 0.98759 \\
TRIMHX & Power & 0.98758 \\
GRIMHX & Production & 0.98759 \\
TRIMHX & Production & 0.98758 \\
\hline
\end{tabular}




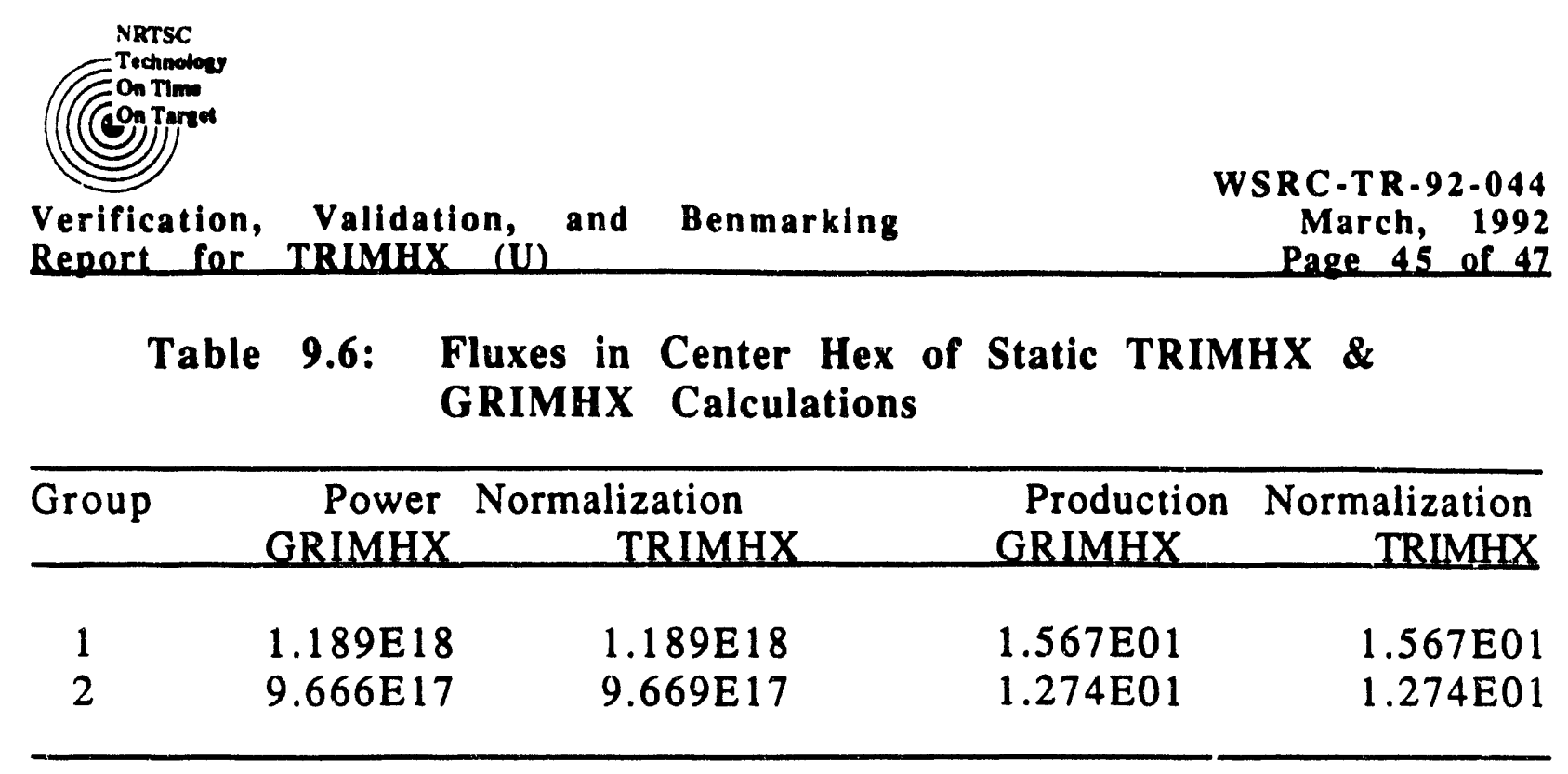

\section{CONCLUSIONS}

TRIMHX has been verified and validated by comparing the results of test problems to the exact solutions, measured data, and other codes' calculated results. For the initial $k_{e f f}$, initial flux distributions, and transient flux distributions, TRIMHX solutions show very good agreements with other results. It is the conclusion of this study that TRIMHX correctly implemented the theory and that TRIMHX is certified for use in production calculations. 
WSRC.TR-92.044

March, 1992

Beferences

Page 46 of 47

\section{REFERENCES}

1. Bell, G. I. and Glasstone, S., Nuclear Reactor Theory, Huntington, New York: Robert E. Krieger Publishing Company 1979.

2. Lamarsh, J. R., Introduction to Nuclear Reactor Theory, Reading, Mass.: Addison-Wesley Publishing Co., Inc. 1966.

3. T. T. Le, User's Manual for GRIMHX and TRIMHX: Three Dimensional Hexagonal Static and Transient Diffusion Theory Codes (U), WSRC-TR91-663, May 1992.

4. DPSTM-500 Joshua Manual, Volume 10, "Module TRIMHX - Transient Reactor Iterative Module in Hexagonal Geometry", November 1973 (Draft).

5. H. Toffer, R. D. Crowe, K. N. Schwinkendorf, R. E. Pevey, Verification and Validation Plan for Reactor Analysis Comp ter Code (U), WSRCRP-89-1249, November 1989.

6. M. R. Buckner, and J. W. Stewart, "Multidimensional Space-Time Nuclear-Reactor Kinetics Studies - Part I: Theoretical," Nuclear Science and Engineering, 59, pp 289-297, (1976).

7. P. B. Parks, and J. W. Stewart, Comparison of Pulsed Neutron Experiments and Diffusion Theory Space-Time Calculations, DP-1352, (1974).

8. E. F. Trumble, Validation and Verification Summary Report for GRIMHX and TRIMHX (U), WSRC-TR-90-594, December 1990.

9. P. B. Parks, N. P. Baumann, R. L. Currie, and C. E. Jewell, "Multidimensional Space-Time Nuclear-Reactor Kinetics Studies - Part II: Experimental," Nuclear Science and Engineering, 59, pp 298-310, (1976). 
WSR C.T R.92.044

March, 1992

References

Page 47 of 47

10. W. G. Winn, P. B. Parks, N. P. Baumann, and C. E. Jewell, "Multidimensional Space-Time Nuclear-Reactor Kinetics Studies - Part III: ThreeDimensional Experiments," Nuclear Science and Engineering, 65, pp 254-272, (1978).

11. W. E. Graves, Comparison of Space-Time Calculational Methods for East Scram Applications, DPST-88-749, August 1988.

12. J. A. Smith and J. P. Church, Accident Analysis Computer Program, DPSTM-120, March 1984.

13. T. A. Taiwo and H. S. Khalil, "The DIF3D Nodal Kinetics Capability in Hex-Z Geometry Formulation and Preliminary Tests", Proceeding of the International Topical Meeting Advances in Mathematics. Computations, and Reactor Physics, April 28 - May 2, 1991.

14. R. A. Shober, T. A. Daly, and D. R. Ferguson, EX2-TH: A TwoDimensional Nuclear Reactor Kinetics Code with Thermal-Hydraulic Eeedback, ANL-78-97, Argonne National Laboratory, October 1978.

15. E. F. Trumble, Changes to TRIMHX Coding (U), WSRC-RP-89-1169, October 1989.

16. W. H. Reed, H. C. Honeck, J. T. McCort, and B. W. Westmoreland, The Joshua Users' Manual, DPSPM-GEN-36, September 14, 1987. 

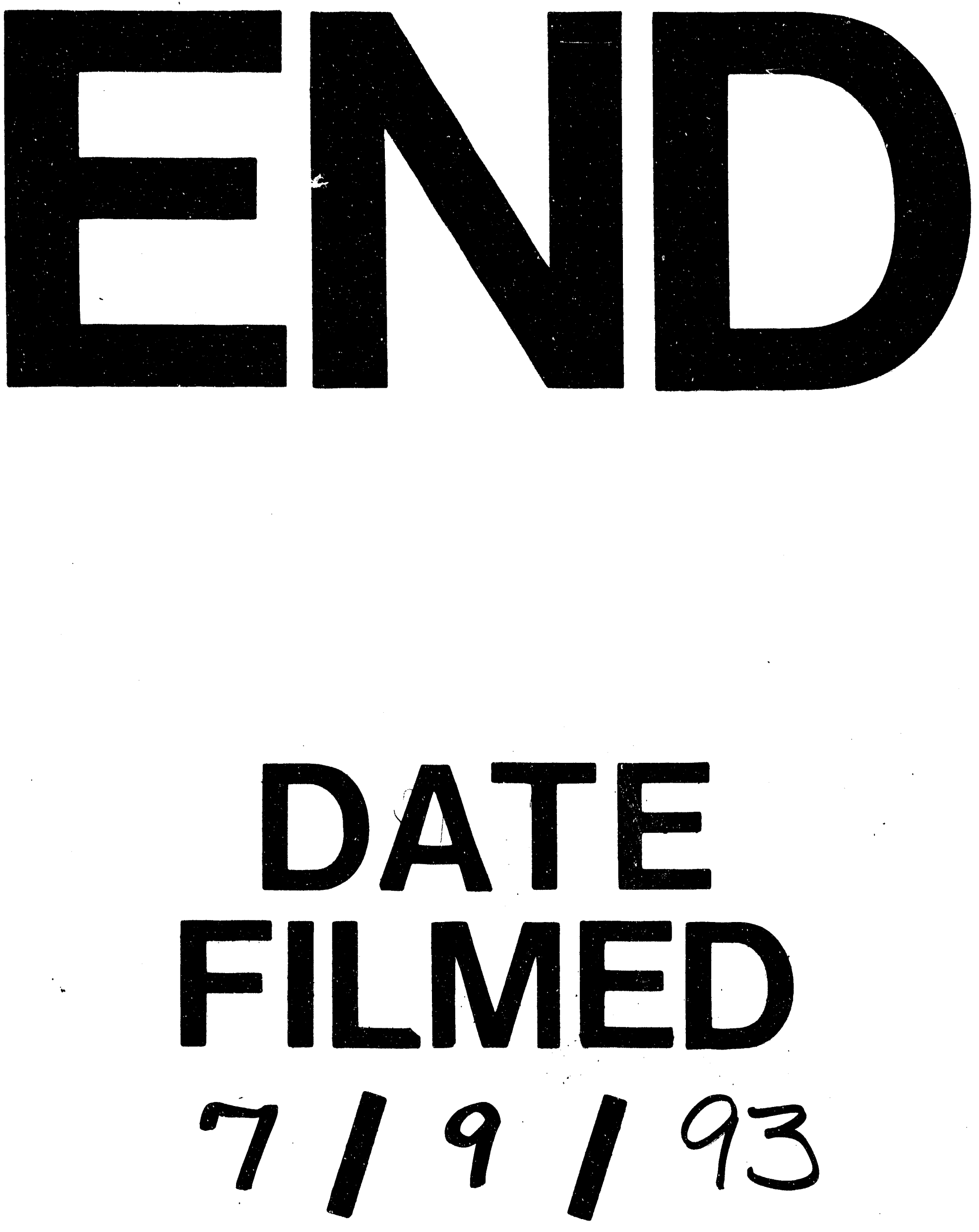

1 
